\title{
Register in the round: registerial cartography
}

\author{
Christian MIM Matthiessen
}

\author{
Correspondence: \\ cmatthie@mac.com \\ Department of English, \\ PolySystemic Research Group, \\ Faculty of Humanities, The Hong \\ Kong Polytechnic University, Hong \\ Kong, Hong Kong
}

\begin{abstract}
Registerial cartography is the activity of systematically describing the registers that make up a language - with register in its original sense of a functional variety of a language, i.e. of the adaptation of the meaning-making resources of a language according to context of use. A register map of a language would thus show its composition of registers - of meanings at risk in the various cultural domains that constitute a culture. This variation according to use - register variation - is located along the cline of instantiation between the overall meaning potential of a language operating in the context of culture and the instantiation of this meaning potential unfolding as texts in contexts of situation.

In this paper, I will report on a long-term register cartography project concerned with the analysis and description of the registers that collectively constitute the meaning potential of a language. The maps produced as part of the project are based on context in the first instance, since register variation is precisely variation according to context of use. Thus registers can be located within the map according to the "Iongitude and latitude" of context, i.e. according to the contextual parameters of field, tenor and mode. Here I will focus on a field-based map, more specifically one based on a typology of fields of activity - a characterizations of different goings-on in context. This typology differentiates eight primary types of field of activity, 'expounding', 'reporting', 'recreating', 'sharing', 'doing', 'enabling', 'recommending' and 'exploring', and their secondary and tertiary subtypes. I will then illustrate how texts operating in contexts characterized by these different fields of activity are organized semantically in terms of logico-semantic (rhetorical) relations (based on a version of RST, Rhetorical Structure Theory), showing that different relations are "at risk" depending on the nature of the field of activity. I will round off the paper by discussing how field-based maps of registers have and can be used in different areas of application.
\end{abstract}

\section{Introduction}

In this paper, I will give an interim report on a long-term project concerned with what might be called registerial cartography, with register in its original sense in linguistics of a functional variety of language. This is the task of creating maps showing functional varieties of a language operating in different contexts of use, representing these functional varieties as regions within the overall space of meaning of that language. More technically, registerial cartography is the task of mapping out registerial variation falling within the range intermediate between the two poles of the cline of instantiation - between the system (potential) pole and the text (instance) pole (Halliday 1991, 2002). This range includes various kinds of variation in the instantiation of the system at the potential pole of the cline - both codal variation and registerial variation (cf. Hasan 1973; Halliday 1994); but here I will be concerned with the registerial part of the range - with variation 
according to the context of use (e.g. Halliday et al. 1964; Halliday 1978; and contributions to Ghadessy 1988, 1993): for a recent review register studies, see Lukin et al. (2008).

When, around two decades, ago Mohsen Ghadessy asked me to write the final chapter (Matthiessen 1993) for his excellent collection of papers on different aspects of Register Analysis (Ghadessy 1993), I read the insightful contributions to the volume and surveyed what had been done more generally in SFL up to that point, and I arrived at the conclusion that while it was important to continue to develop the theory of register, the highest priority was to develop many more extensive accounts of registers - either by describing registerial subsystems (see e.g. Halliday's 1973, description of regulatory semantics - of the semantic strategies available to a mother to control a young child's behaviour) or by generalizing from large-scale analysis of samples of texts (as in Nanri's 1993, study of news reports concerned with (attempted) assassinations), the two being complementary approaches to the characterization of registers (see Figure 1). Such an effort would be of significant value in its own right, but it would also inform further theoretical developments. One could envisage a "human sememe project" as a semiotic analogue of the human genome project; and an important part of such a project would be largescale registerial cartography for a wide range of languages.

Whenever I have had the opportunity, I have tried to work on - or perhaps rather towards - such a project, together with colleagues and students doing research in different areas, including language description, language comparison and typology, translation studies, language teaching and learning, healthcare communication. There has never been a separate dedicated project with research funding, but we have tried to develop the work in a range of different contexts. This has involved both fresh analyses and descriptions, and surveys of existing analyses and descriptions produced by colleagues.

In this paper, I will report on some aspects of this long-term project. I will begin by fleshing out the notion of registerial cartography (Section 2), locating the territory to be

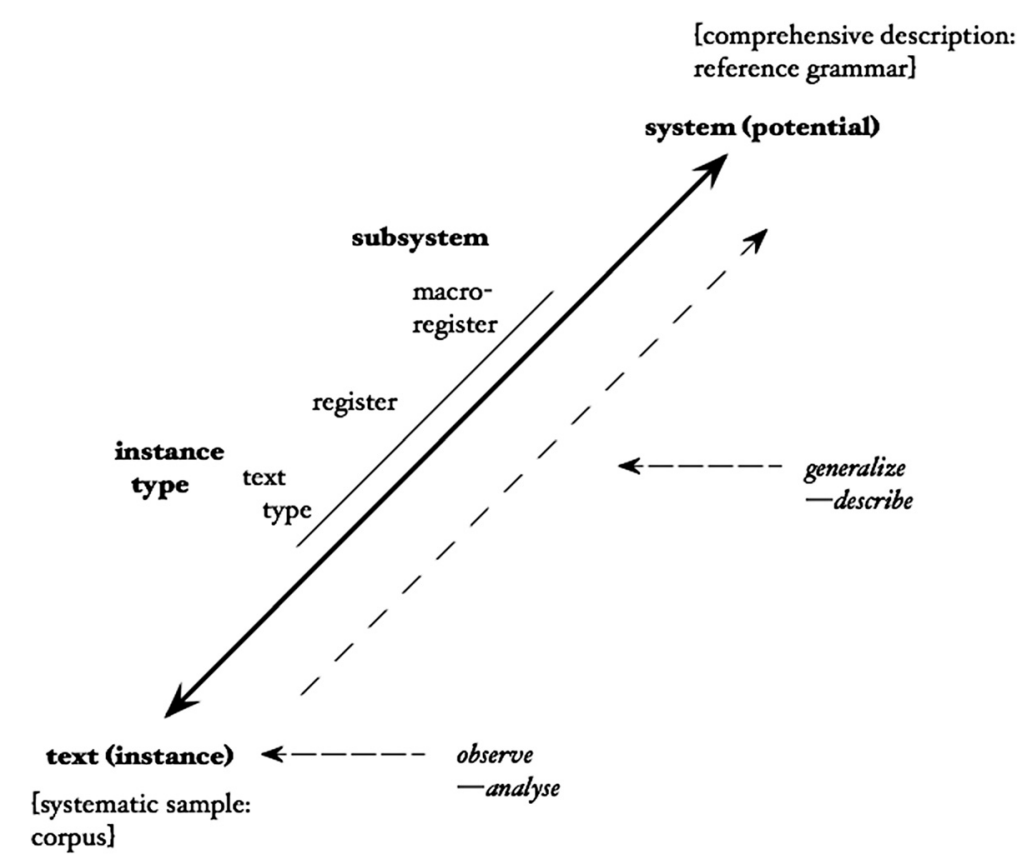

Figure 1 Registerial cartography — complementary approaches: text analysis, system description. 
surveyed in registerial cartography in terms of two of the global dimensions in the organization of language in context, viz. the cline of instantiation and the hierarchy of stratification. Here I will suggest that registerial cartography must be based on parameters within context in the first instance - that is, on field, tenor and mode. In the next section (Section 3), I will choose one of these contextual parameters, viz. field or more specifically, the field of activity within context - as the starting point for registerial cartography. Drawing on work by Jean Ure, I will identify eight primary fields of activity (for earlier discussions, see Matthiessen 2006; Teruya 2007; Matthiessen et al. 2010), and suggest secondary types within these primary fields of activity, based on our exploratory research. By extending the account of fields of activity in delicacy, we can make contact with the rich body of work on genre agnation (e.g. Martin 1992a; Christie and Martin 1997; Martin and Rose 2008). Having reached this stage, we can begin to explore how situation types ("genres") are realized semantically (Section 4). Here I will draw on Hasan (1984) work on the semantic realization of elements of generic structure, suggesting that patterns of semantic realization can be characterized in terms of logicosemantic complexes with the help of Rhetorical Structure Theory (RST; e.g. Mann William and Thomposon et al. 1992). This is then also the basis for taking the next step down in the hierarchy of stratification, from semantics to lexicogrammar.

\section{Registerial cartography}

The metaphor of cartography

Registerial cartography can be seen as a process of filling in certain descriptive gaps in our account of language in context (or, more generally, of language and other denotative semiotic systems in context $\mathrm{t}^{\mathrm{a}}$ ) - that is, filling in gaps that we have been able to identify when we survey the territory of meaning. Where are these descriptive gaps located? Well, we can locate them in terms of the semiotic analogue of longitude and latitude. But let me first say a few words about the metaphor of cartography applied to semiotic systems.

Cartography, or "the science or practice of drawing maps", has of course been developed as a way of observing, describing and modelling material territories, with a certain focus (e.g. topographic, political, demographic) and based on some form of projection system (see e.g. Thrower 2008). I have simply transferred "cartography" from the material realm to the immaterial realm, more specifically to the semiotic realm - cf. my notion of "lexicogrammatical cartography" in Matthiessen (1995a). This is similar to, and related to, the transfer of "geography" from the material to the immaterial, as in the development of the discipline of "cultural geography" and as in Gu (2002) notion of "discourse geography".

Underlying both these metaphors is the general semogenic principle embodied in languages whereby models of concrete space are transferred and adapted to the modelling of our experience of abstract realms (see e.g. Matthiessen 1992; Halliday and Matthiessen 2006, and references therein); for example:

Rising Greek Political Star, Foe of Austerity, Puts Europe on Edge [NY Times, 19 May 2012]

Having covered up the extent of the problem and failed to take early preventative measures, the Chinese authorities are now scrambling to demonstrate that they have the situation under control. [WSWS, 3 May 2003] 
The dollar had already been climbing on short-covering against the yen, after dealers began buying back the currency on its fall early in the session to 133.03 yen, which was the currency's lowest level since May 12. [Dow Jones, 7 October 1998]

Just as the dimensionality in models for construing our experience of concrete space is a powerful resource for construing our experience of abstract realms, so the dimensionality of the map can be helpful in surveying territories of meaning: maps are among other things helpful tools for visualizing territories of meaning (cf. Steele and Iliinsky 2010). Thus notions such as "semantic maps" and "mind maps" have become popular, usually taking the form of some kind of graph consisting of links between nodes representing senses or meanings that are related in one way or other.

\section{Registerial cartography in relation to instantiation and stratification}

Ordinary maps are based on two coordinates, longitude and latitude - the vertical and horizontal dimensions used in different projection systems. What are the semiotic equivalents of these two dimensions used in surveying physical territories? It turns out, not surprisingly, that there are a number of candidates: semiotic space is multidimensional. However, for present purposes we can begin with two of these - the cline of instantiation and the hierarchy of stratification, exploring the spectrum of metafunction later. By using these two semiotic dimensions, we can identify the descriptive gaps that can be filled in by means of registerial cartography (see Figure 2):

- In terms of the cline of instantiation, we need to continue to develop linguistic accounts of the region between system and instance. We can develop these accounts descriptively, approaching the region from the system end and describing subsystems based on descriptions of the overall system, or text-analytically, approaching the region from the instance end and making generalizations based on the results of the analyses of samples of texts.

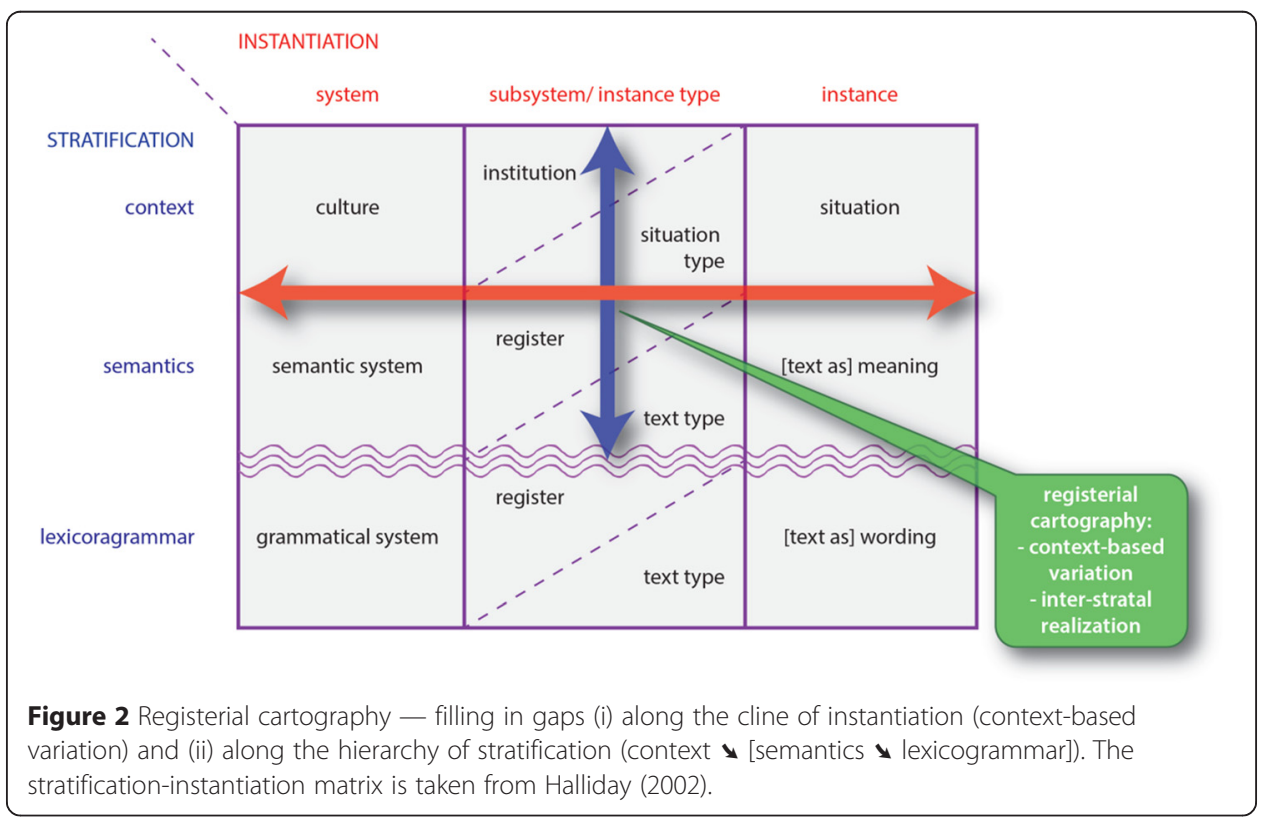


- In terms of the hierarchy of stratification, we need to relate contextual patterns stated in terms of field, tenor and mode to semantic patterns (and then, by another step, to lexicogrammatical patterns [cf. Lam and Webster 2009]). Contextual patterns along the syntagmatic axis have been described in terms of generic (schematic) structures; here the task is to describe how elements of generic structure are realized semantically, thus continuing the project outlined and initiated by Hasan (1984).

These two dimensions can be intersected to define an instantiation-stratification matrix, as in Halliday (2002): see Figure 2. In this matrix, I have indicated the territory that registerial cartography is concerned with - between system and instance in terms of the cline of instantiation (as already noted), and within the content plane of language in reference to context (again as already noted) - semantics and lexicogrammar, the latter being mediated by the former.

The task in registerial cartography is thus to map out a region of semantic space in such a way that the features of this region reflect the diversification of context into institutions and, within these, situation types. Thus registerial cartography needs to be based on considerations of context, which makes excellent sense. At the instance pole of the cline of instantiation, we characterize text by referring to context of situation - a text is language functioning in a situation (see e.g. Halliday and Hasan 1976). As we move further up the cline of instantiation, we can group texts that are alike in crucial respects into text types, characterizing a text type as language functioning in a situation type. And if we start from the potential pole of the cline, we relate the semantic system to the context of culture, and if we move down the cline of instantiation, we can identify semantic subsystems or registers within subcultures or institutional domains, characterizing a register as language functioning in an institutional domain.

\section{Context-based registerial cartography}

If, as just suggested, we interpret a register as language functioning in an institutional domain, it makes sense to base registerial cartography on context to begin with: since register variation is functional variation in the semantic system according to the context of use, we can draw our map based on the contextual variables of field, tenor and mode and use this map to represent the overall registerial range of English. We can think of this registerial range as a sphere of meaning determined by field, tenor and mode: see Figure 3. This is of course a simplified picture since field, tenor and mode are not single dimensions but rather each is a set of parameters (cf. for example, Halliday 1978; Martin 1992a; Hasan 1999).

Building on Jean Ure's unpublished index to a text anthology accompanying her book manuscript on discourse analysis, we have used and developed this index in various areas of research and application, including work on language description, translation studies and educational linguistics (e.g. Matthiessen 2006: 44-46; Teruya 2007: 12; Matthiessen et al. 2010: 221).

Ure's index was based on field - more specifically, field of activity (as opposed to field of experience, or "subject matter"), and mode - more specifically on medium (spoken/ written) and turn (dialogic/monologic). We have worked with these, interpreting the eight primary fields of activity that she identified, and extending them further in delicacy, and intersecting them not only with mode but also with tenor. 


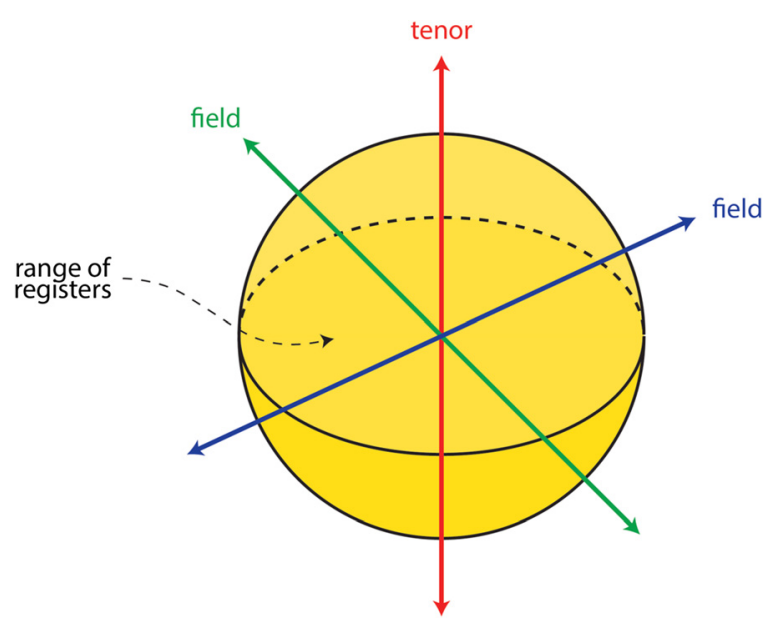

Figure 3 Register variation as a sphere of meaning — registerial range within field, tenor and mode values in context.

As I present the context-based registerial map, I will start with field of activity within field. The field of activity is "what's going on" in context (cf. Halliday 1978; Hasan 1994). The activity is either primarily social or primarily semiotic - i.e. either primarily a process of interactive behaviour or one of exchanging meaning. ${ }^{\mathrm{b}}$ To capture this, I have called this parameter SOCIO-SEMIOTIC PROCESS. We can represent this parameter topologically as a circle with eight sectors - expounding, reporting, recreating, sharing, doing, recommending, enabling and exploring — as shown to the right in Figure 4; let me give one example of each primary type:

- expounding: contexts where natural phenomena such as cold fronts are explained to help readers or listeners as part of the construction "knowledge" about general classes of phenomena.

- reporting: contexts where the flow of particular human events are chronicled to help readers or listeners construct keep up with or review events.

- recreating: contexts where the flow of particular human imaginary events are narrated to achieve some kind of aesthetic effect.

- sharing: contexts where personal values and experiences are exchanged to help interactants relate to one another for example by calibrating their sense of moral values in a work place.

- doing: contexts where people are engaged in a joint social activity, using language to facilitate the performance of this activity.

- enabling: contexts where a course of action is modelled semiotically and made possible through instruction.

- recommending: contexts where a course of action is advised for the benefit of the addressee.

- exploring: contexts where public values and ideas are put forward and debated.

To complement this topological representation of the parameter, we can also represent it typologically, or systemically; and when we do so, the question immediately arises of whether the eight different types are simply simultaneous terms in one system, 


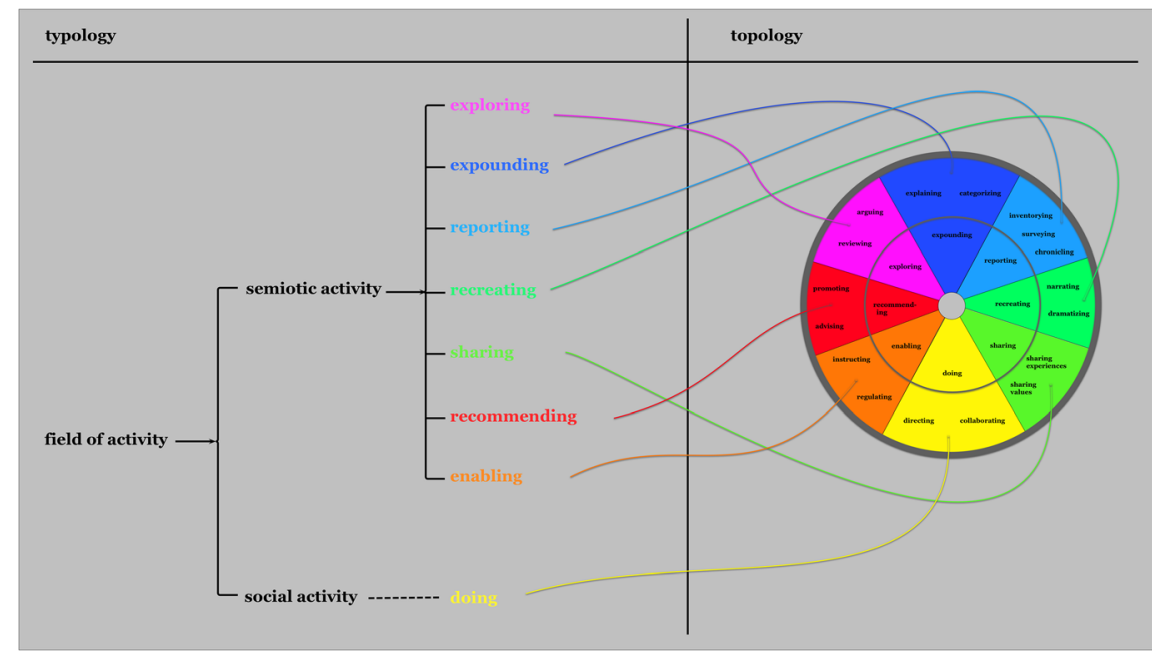

Figure 4 Field-based map of registerial range represented typologically and topologically.

or can be ordered in delicacy. If we order them in delicacy, we can bring out the distinction between primarily social activities (behaving) and primarily semiotic ones (meaning), as shown to the left in Figure 4.

Figure 4 shows the correspondence between the systemic terms in the typological representation and the regions in the topological representation (for a general discussion of systemic typology and topology, see Martin and Matthiessen 1991). These two forms of representation are complementary. (i) In the systemic typology, it is easier to bring out (1) ordering in delicacy - indeed, as soon as we represent linguistic or contextual resources in this way, we must confront issues having to do with ordering in delicacy, and (2) simultaneity in delicacy - that is, intersecting variables. (ii) In systemic topology, it is easier to bring out certain kinds of indeterminacy (cf. Halliday and Matthiessen 2006, on types of indeterminacy), in particular overlaps ('both a and b') and blends ('partly c, partly d'): overlaps and blends are ways in which regions of the topology shade into one another (see further Matthiessen and Teruya, 2015, on registerial hybridity).

In what follows, I will begin by extending the description of fields of activity - of socio-semiotic process - in delicacy up to the point where it is possible to make contact with the extensive body of accounts of "genres" documented by e.g. Martin (1992a, 1992b), Martin and Rose (2008), Christie and Derewianka (2008) and Eggins and Slade (2005).

Having extended the description of the field of activity in delicacy, I will then combine field values certain values from tenor and mode parameters to illustrate the cartographic power of this descriptive framework.

\section{Field-based registerial cartography: extension in delicacy}

The registerial map in Figure 4 above identifies the primary fields of activity, or sociosemiotic process types. These low-delicacy distinctions are very important in registerial cartography; for example, they give us insight into the registerial profiles of different secondary school subjects and different university disciplines, as I will illustrate in 
Section 6.1 below (cf. Matthiessen 2009a). However, the primary distinctions are too indelicate - too general - to allow us to specify the contextual structures. ${ }^{\text {c }}$ For instance, 'expounding' contexts cover both contexts of 'explaining' and contexts of 'documenting' or 'categorizing', and these contexts tend to be staged in different ways. In fact, here we would have to take at least one step further in the delicacy of differentiation of fields of activity to be able to state contextual structures: the structure of an explanation will depend on what kind of explanation it is - e.g. sequential or factorial (see e.g. Veel 1997; Martin and Rose 2008).

The extension in the delicacy of the description of field of activity will have at least two immediate pay-offs. On the one hand, this extension will give us a better sense of what the primary types cover; for example, differentiating 'recommending' into 'promoting' and 'advising' gives a clearer sense of the intended beneficiary of a recommendation (speaker and addressee, respectively). On the other hand, the extension in delicacy will make it easier to relate the account to all the work on genre in SFL, summarized by Eggins and Slade (2005), for spoken language, and by Martin and Rose (2008), for written language: see Tables 1 and 2. There will also be other benefits, in particular areas of research and application. For example, in educational linguistics, the extension in delicacy will help us represent learner pathways (e.g. Christie and Derewianka 2008), resulting in progressive expansions of learners' registerial repertoires (see Matthiessen 2009a).

Extending the account of field of activity in delicacy is an ongoing project, but let me represent the first exploratory extension in delicacy for the eight primary types in Figure 5 . These secondary types can be characterized briefly as follows:

- expounding our experience of classes of phenomena according to a general theory (ranging from commonsense folk theories to uncommonsense scientific theories [see e.g. Halliday and Matthiessen 2006: Ch. 14]) - either by categorizing (or "documenting") these phenomena or by explaining them;

- reporting on our experience of particular phenomena - chronicling the flow of particular events (as in historical recounts or news reports), surveying particular places (as in guide books) or inventorying particular entities (as in catalogues);

- recreating our experience of the world imaginatively, that is, creating imaginary worlds having some direct or tenuous relation to the world of our daily lives recreating the world imaginatively through narration and/ or through dramatization;

- sharing our personal lives, prototypically in private, thereby establishing, maintaining and negotiation personal relationships - sharing our personal experiences and/ or sharing our personal values;

- doing social activities, prototypically engaging in interactive social behaviour, thereby collectively achieving some task - either by members of one group collaborating with one another or by one person directing the other members of a group;

- enabling people to undertake some activity, thus very likely foreshadowing a 'doing' context - either by instructing them in how to undertake the activity or by regulating their behaviour;

- recommending people to undertake some activity, thus very likely foreshadowing a 'doing' context - either by advising them (recommendation for the benefit of the addressee, as in consultations) or inducing them (promotion: recommendation for the benefit of the speaker, as in advertisements); 
Table 1 Terms in the system of socio-semiotic process (field) and "genres" described in Martin and Rose (2008) and Eggins and Slade (2005)

\begin{tabular}{|c|c|c|c|}
\hline \multicolumn{2}{|c|}{ SOCIO-SEMIOTIC PROCESS } & $\begin{array}{l}\text { Martin \& Rose (2008): } \\
\text { "Genre model" }\end{array}$ & $\begin{array}{l}\text { Eggins \& Slade } \\
(2005)\end{array}$ \\
\hline \multirow[t]{2}{*}{ expounding } & explaining & $\begin{array}{l}\text { (Chapter } 4 \text { Reports and Explanations) } \\
\text { explanations }\end{array}$ & \\
\hline & categorizing & (Chapter 4 Reports and Explanations) reports & \\
\hline \multirow{3}{*}{ reporting } & chronicling & $\begin{array}{l}\text { (Chapter } 3 \text { Histories) recounts, biographies } \\
\text { (Chapter } 5 \text { Procedures and procedural } \\
\text { recounts) procedural recounts }\end{array}$ & \\
\hline & surveying & & \\
\hline & inventorying & & \\
\hline recreating & $\begin{array}{l}\text { [narrating, } \\
\text { dramatizing] }\end{array}$ & (Chapter 2 Stories) stories: narratives & \\
\hline sharing & $\begin{array}{l}\text { [experiences, } \\
\text { values] }\end{array}$ & (Chapter 2 Stories) stories: anecdotes, exempla & $\begin{array}{l}\text { chat; opinion, } \\
\text { teasing, gossip }\end{array}$ \\
\hline doing & $\begin{array}{l}\text { [directing, } \\
\text { coordinating] }\end{array}$ & & \\
\hline \multirow{2}{*}{ recommending } & promoting & & \\
\hline & advising & & \\
\hline \multirow[b]{2}{*}{ enabling } & instructing & $\begin{array}{l}\text { (Chapter } 5 \text { Procedures and procedural } \\
\text { recounts) procedures }\end{array}$ & \\
\hline & regulating & $\begin{array}{l}\text { (Chapter } 5 \text { Procedures and procedural } \\
\text { recounts) protocols <or: embedded in } \\
\text { procedures }>\end{array}$ & \\
\hline exploring & arguing & (Chapter 3 Histories) expositions, discussions & \\
\hline
\end{tabular}

- exploring our communal values and positions, prototypically in public - either by reviewing a commodity (goods-\&-services) or by arguing about positions and ideas.

These types and subtypes shade into one another; there are various hybrid types involving overlaps, blends and neutralizations (cf. Halliday and Matthiessen 2006) — but this hybridity can be brought out and described precisely because we have identified prototypical types and subtypes.

For one of the eight types - 'expounding' - I have suggested one further step in Figure 5, into tertiary delicacy; this step is based on the work on genre typology

Table 2 Recurrent temporal nucleus + satellite combination in Text 4

\begin{tabular}{|l|l|l|}
\hline$\#$ & nucleus $\searrow \alpha$ & satellite $\searrow \times \beta$ \\
\hline$[0]$ & {$[0.1]$ Two Australians missing } & {$[0.2]$ as storm sinks Thai ferry } \\
\hline$[1]$ & $\begin{array}{l}{[1.1] \text { Two Australian women are among 20 people }} \\
{[\text { feared dead] }]}\end{array}$ & $\begin{array}{l}{[1.2] \text { after a ferry sank off the coast }} \\
\text { of Thailand. }\end{array}$ \\
\hline$[2]$ & $\begin{array}{l}{[2.1] \text { Naomi Mary Leslie, 24, of Perth, and Grabrielle }} \\
\text { Sandercock, 33, reportedly from Melbourne, were } \\
\text { on board the ferry }\end{array}$ & $\begin{array}{l}{[2.2] \text { when it overturned on its way }} \\
\text { to thland of Koh Tao on } \\
\text { Wednesday. }\end{array}$ \\
\hline$[10]$ & $\begin{array}{l}[10.1] \text { Many of those [[who died] }] \text { were trapped } \\
{[10.2] \text { when water gushed into the }} \\
\text { boat's cabin. }\end{array}$ \\
\hline
\end{tabular}




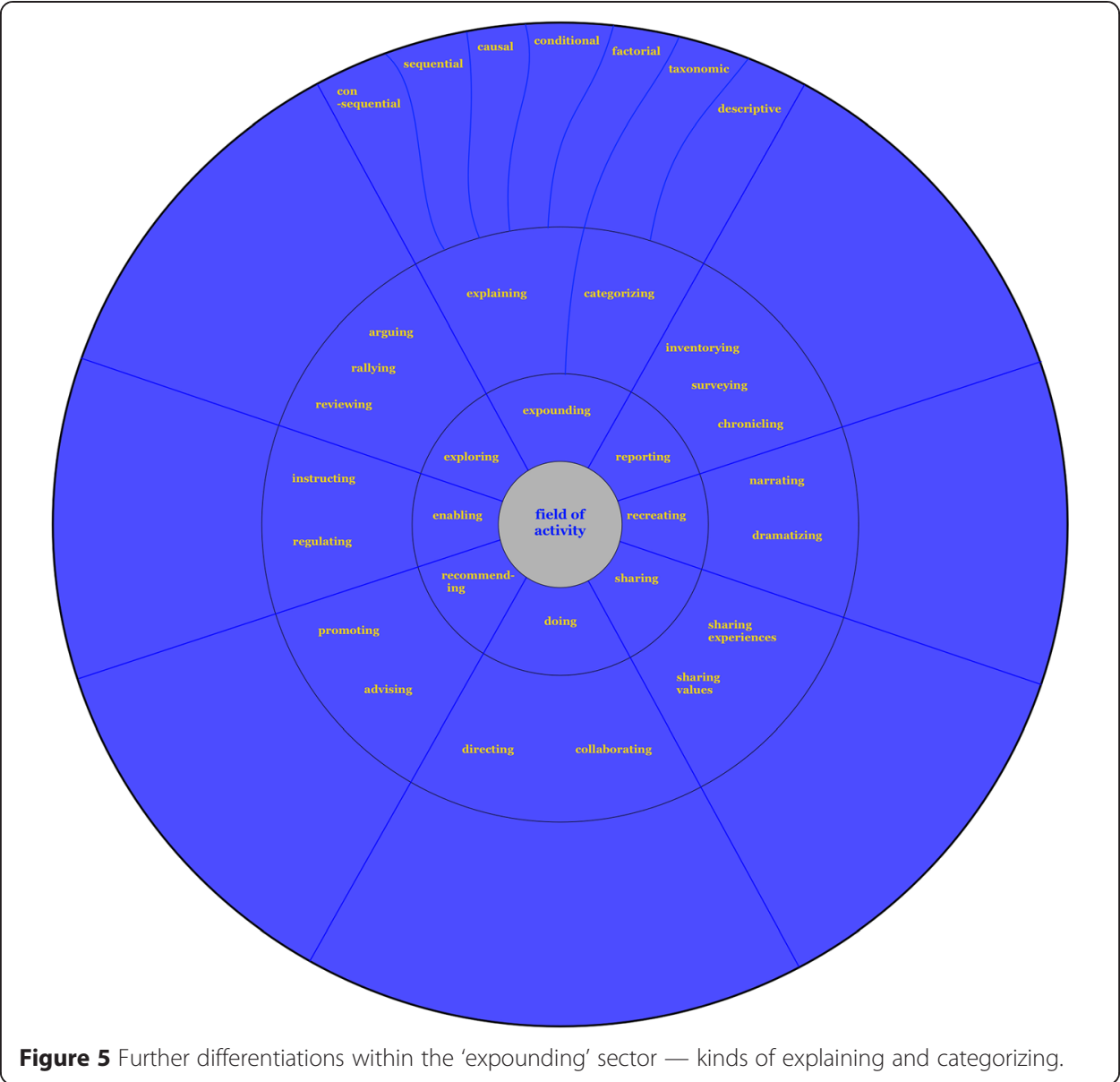

presented in e.g. Veel (1997) and Martin and Rose (2008). In fact, tertiary subtypes could be organized further in typological groupings. For example, with some change in the names of the more delicate types, the field of activity of 'explaining' could be further differentiated in a few steps, e.g. 'sequential' ('temporal sequence,' implicational sequence') vs. 'non-sequential' ('conditional' [or 'theoretical'], 'causal', with the latter further differentiated into 'consequential', 'factorial'): see Figure $6^{\mathrm{d}}$. This is not the only way of organizing the region systemically; but the version shown in Figure 6 clearly provides much more information than a flat list of fields of activity.

Certain systemic terms in the systems of the socio-semiotic process (field of activity) network in Figure 6 have realization statements associated with them. These realization statements specify fragments of the structure of the situation type (the structural description comes from Veel 1997). For example, 'non-sequential' is realized by the presence of the contextual element of Phenomenon Identification ('nonsequential' $\searrow+$ Phenomenon Identification), and 'factorial' is realized by the presence of (one or more instances of) the element Factor after Phenomenon Identification: $\searrow$ Phenomenon Identification $\wedge+$ Factor $^{1-n}$, which is shorthand for $\searrow+$ Factor $^{1-n}$; Phenomenon Identification ${ }^{\wedge}$ Factor $^{1-\mathrm{n}}$. In other words, the kind of potential that is built into Hasan $(1978,1984)$ ) specifications of generic structure potential (GSP) is represented systemically here - which is, of course, in line with her theory of context. 


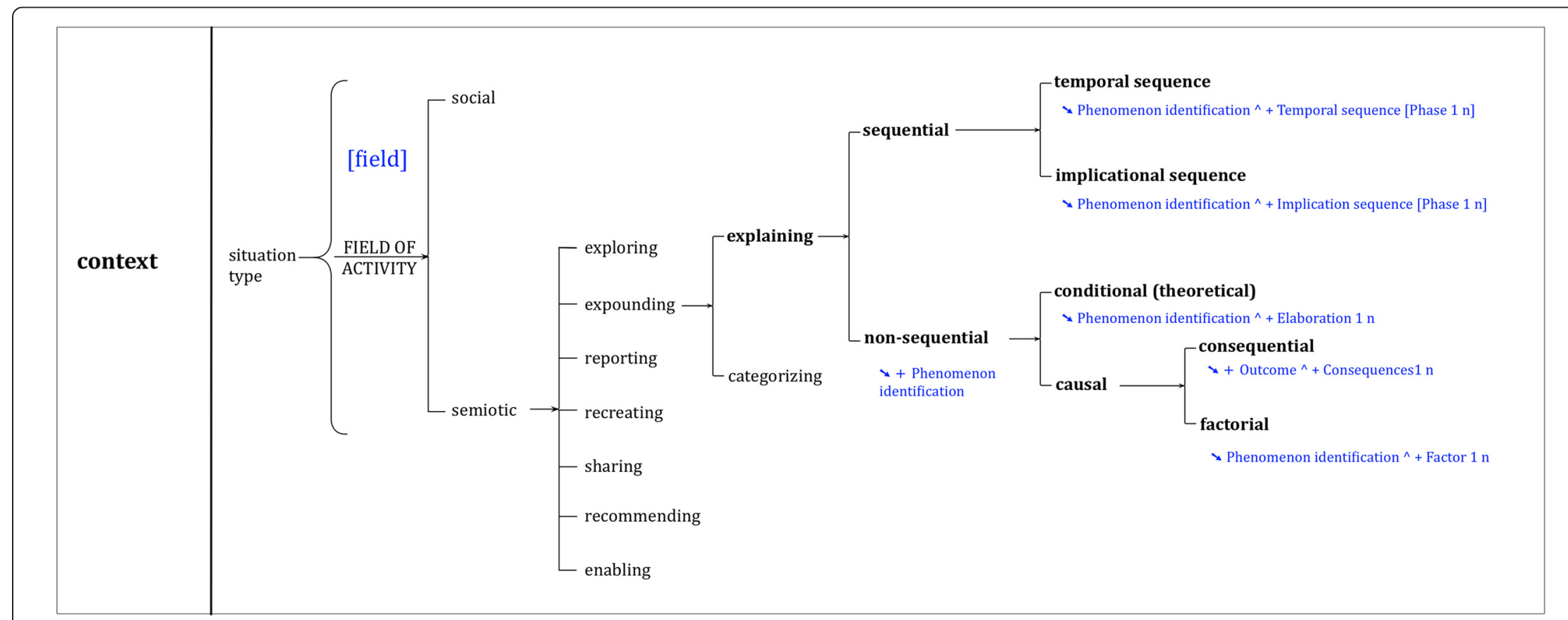

Figure 6 Systemic organization of types of 'explaining' - three steps in delicacy. 
The realization statements in Figure 6 are inter-axial but intra-stratal: that is, they relate paradigmatic order to syntagmatic order within the stratum of context. But contextual realization statements can, of course, also refer to patterns below the stratum of context - inter-stratal realization statements. If contextual elements are realized linguistically, these patterns are semantic ${ }^{\mathrm{e}}$; that is, contextual elements are realized by patterns of meaning, as shown by Hasan, Ruqaiya (1984)). Let me now explore semantic realization in some more detail.

\section{Patterns of semantic realization}

An example: a factorial explanation

Contextual elements are usually realized semantically, as Hasan, Ruqaiya (1984)) shows in detail for the Placement element of traditional nursery tales (cf. Matthiessen 2014). I will illustrate the semantic realization of contextual elements in reference to 'factorial' explanations within the expounding sector of Figure 5. As shown in Figure 6, the contextual structure is Phenomenon Identification ${ }^{\wedge}+$ Factor $^{1-n}$; Veel (1997) provides the text reproduced in Text 1 as an example.

Text 1: Physical Weathering - an example of a factorial explanation text (from Veel 1997)

Physical Weathering

[1] This process is the cause of the breaking-up of large rocks into smaller pieces. [2] Physical processes can cause changes in rocks.

[3] The two most important methods are changes in temperature and the freeze-thaw changes of water.

[4] Changes in temperature cause the rock to expand and shrink. [5.1] Different parts of the rock expand and shrink by different amounts [5.2] and so the rock is made weaker. [6.1] You have probably seen the effect of freeze-thaw changes of water: [6.2] the size of ice cubes is always larger than the amount of water put into the ice cube trays to make them. [7.1] If water is trapped in a crack in a rock [7.2] and then freezes, [7.3] it can force that crack to widen.

[8] There are also four other processes that are important to the breakdown of rocks. [9.1] Firstly, rocks may be shattered by lightning [9.2] as it strikes high peaks during thunderstorms. [10.1] Only very few people have been on hand [10.2] to see [10.3] how much change this action causes.

[11.1] Secondly, plants assist the breakdown of rocks [11.2] by their roots growing into cracks. [12.1] These cracks may have first formed by temperature changes, [12.2] then widened by ice freezing. [13] The growing roots can widen cracks further.

[14] Thirdly, animals' burrows often loosen and mix soil and rock pieces. [15] This exposes fresh rock to air, wind and water.

[16] Finally, the actions of people cannot be forgotten. [17] We can and do cause changes in rocks much more quickly than any of the natural forces. [18] What natural forces can match bulldozers and dynamite?

Veel (1997: 180-181) analyses the structure of the context of the text in terms of the following contextual elements: 
Phenomenon Identification: [1] - [3]

Factor 1: [4] - [7]

Factor 2: [8] - [10]

Factor 3: [11] - [13]

Factor 4: [14] - [15]

Factor 5: [16] - [18]

When we analyse the text semantically in terms of rhetorical complexes (based on Rhetorical Structure Theory, e.g. Mann, Matthiessen \& Thompson, 1992; see immediately below), patterns emerge that suggest a slightly different contextual analysis:

Phenomenon Identification: [1] - [2]

Factors: [4] - [18]

2 most important factors: [4] - [8]

4 additional factors: [9] - [18]

The rhetorical complex analysis is set out in Figure 7 together with the contextual analysis. Physical Weathering is a fairly short text, and the whole text is organized as a single rhetorical complex, spanning Phenomenon Identification and Factors. Before I discuss the

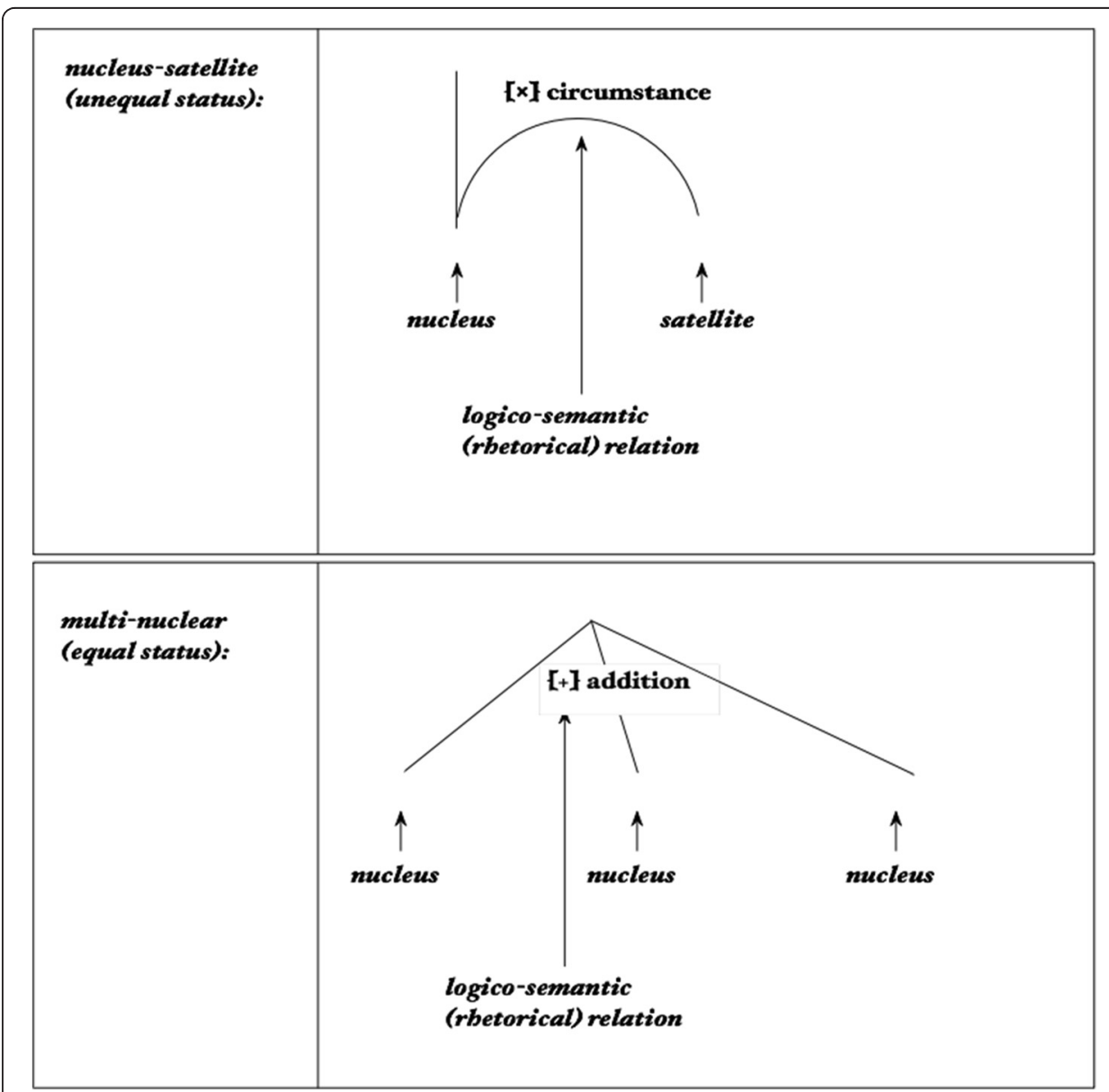

Figure 7 Graphic conventions used in the analysis of texts in terms of rhetorical complexes. 
rhetorical-relational organization of our text as a semantic unit, let me just briefly survey the resources of rhetorical complexing: see Figure 8.

\section{Rhetorical complexing}

Rhetorical complexes are constructed out of rhetorical relations - or logico-semantic relations - such as 'elaboration, 'background' and 'addition'. These relations may link either (i) a nuclear text segment to a supporting satellite or (ii) a nuclear text segment to one or more other nuclear segments. (i) In the former case, the relation is called a nucleus-satellite relation, or mono-nuclear relation. This is like hypotaxis in the grammar of complexing; the two segments being related are of unequal weight, as in the case of 'elaboration'. (ii) In the latter case, the relation is called a multi-nuclear relation. This is like parataxis; the segments being related are of equal weight, as in the case of 'addition'.

Like logico-semantic relations "encoded" in clause complexing, rhetorical relations are thus subject to two systems, one concerned with the nature of the rhetorical relation and one concerned with the degree of interdependence between the segments being related. We can call these systems RHETORICAL RELATION TYPE and RHETORICAL RELATION TAXIS, respectively. The graphic conventions used in the analysis of texts in terms of these two systems are summarized in Figure 7; examples of texts analysed in terms of rhetorical complexes will be given and discussed later (see e.g. Figure 8).

The system of rhetorical relation type covers the logico-semantic types identified by Halliday in his work on the grammar (e.g. Halliday \& Matthiessen, 2004: Ch. 7; Halliday and Matthiessen 2006: Ch. 3). The primary distinction is between 'projection' and 'expansion'. Within 'projection', there is a further distinction between 'locution' and 'idea'; and within 'expansion', there is a further distinction between 'elaborating', 'extending' and 'enhancing'. It is possible to take further steps in delicacy as we describe these systems, but I will stop at this point, and simply list relations belonging to each type (as in the cells in the table included in Figure 9). The system of rhetorical relation taxis (or "nuclearity") is the contrast between 'nucleus-satellite' relations, the hypotactic type, and 'multi-nuclear', the paratactic type.

There is one more system that is familiar from clause complexing. This is the logical system of RECURSION: the contrast between stopping the development of a rhetorical complex ('stop') and augmenting it by introducing an additional rhetorical relation to link to a new text segment ('go on') ${ }^{\mathrm{g}}$. However, there is also one more system, one that is not familiar from clause complexing - at least not as part of the systemic description; but it is familiar from the description of cohesive conjunction, introduced already by Halliday and Hasan (1976), developed by Martin (1992a) and discussed in relation to rhetorical relations by Mann and Matthiessen (1991); see also Chapter 9 of the $4^{\text {th }}$ edition of Halliday's Introduction to Functional Grammar.

This system is the ORIENTATION of the rhetorical relation, either towards interpersonal meaning, internal relations, or towards ideational meaning, external relations. 'Internal' relations link propositions or proposals to one another ${ }^{\mathrm{h}}$; for example, the relation of 'evidence' links one or more propositions where a claim is made to one or more propositions providing an evidential base for the claim. Thus 'internal' relations develop text as interactive moves. 'External' relations link one or more figures to one another; for example, the relation of 'condition' links one or more figures being conditioned to one or more figures conditioning them. Thus 'external' relations link segments of the experience being construed in the text to one another. 


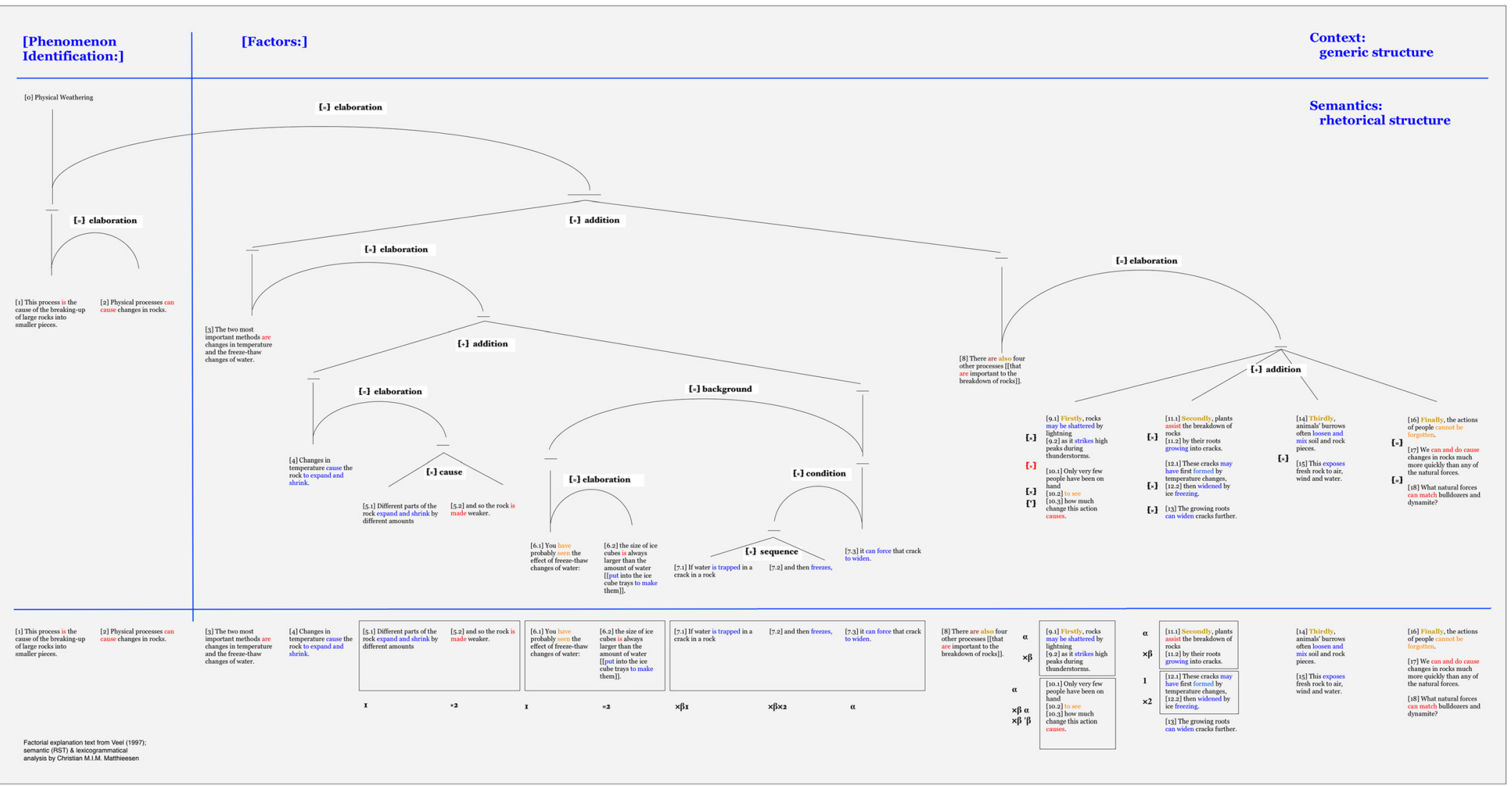

Figure 8 Example of the semantic realization of the elements of contextual structure in a factorial explanation. 


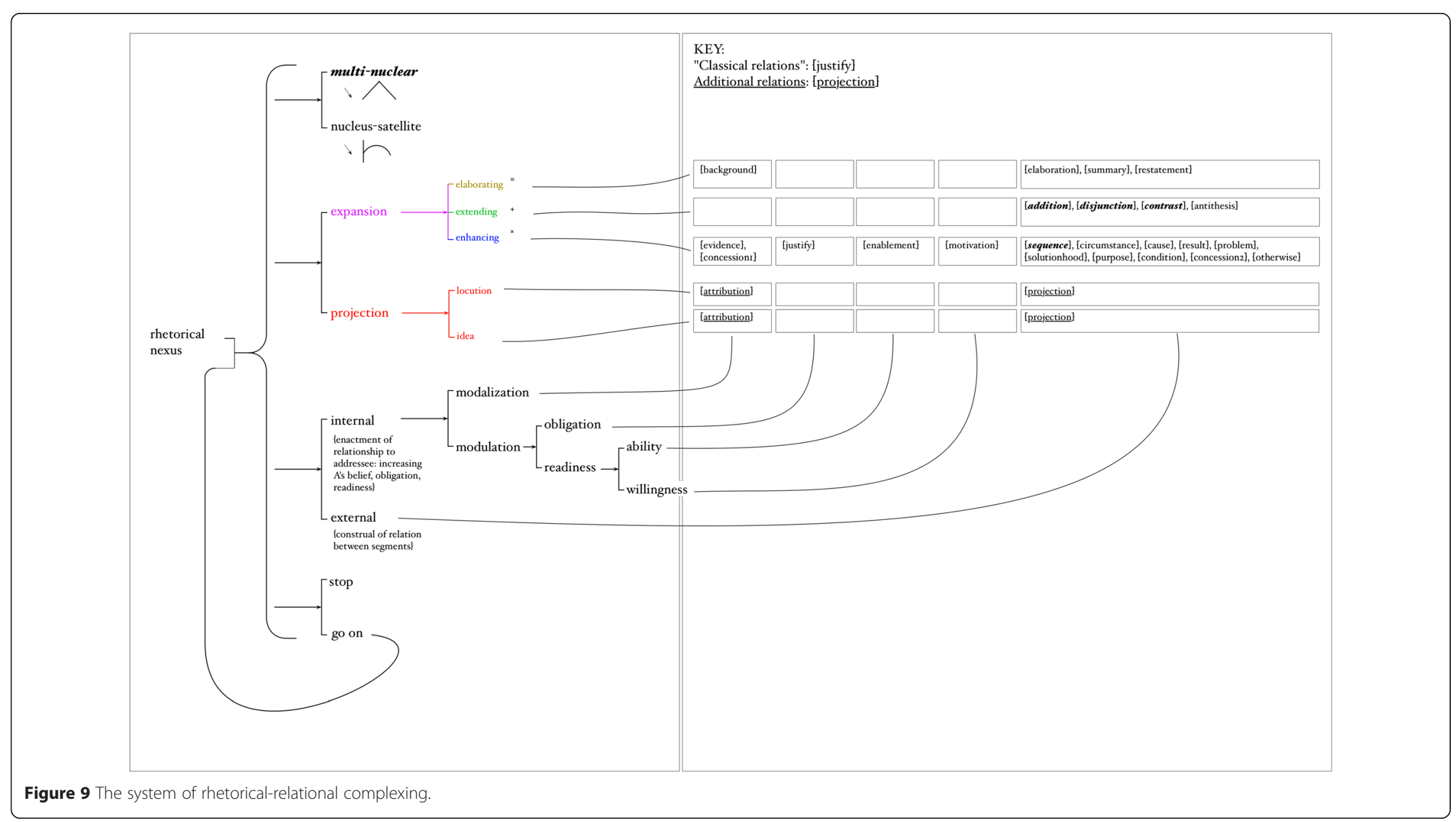


'Internal' relations are often of the 'nucleus-satellite' type: they are deployed to increase the success of a nuclear proposition (or set of propositions) or proposal (or set of proposals); but they can also be 'multi-nuclear', as in internal sequence used to link steps in an argument (firstly, secondly ... furthermore). The increase of the success of the nucleus can be characterized in terms of Halliday's description of the system of Modality (e.g. Halliday \& Matthiessen 2004: Ch. 4 and Ch. 10; cf. also Halliday 1970). If the nuclear segment is one or more propositions, then the increase of success has to do with modalization: probability: the rhetorical relation of 'evidence' is used to link the nucleus to a satellite that provides information that is likely to increase the addressee's belief in the nucleus. If the nuclear segment is one or more proposals, then the increase of success has to do with modulation, relating to obligation, ability or willingness. The rhetorical relation of 'justify' is used to link the nucleus to a satellite that provides information that is likely to increase the addressee's sense of obligation to respond favourably to the proposal - undertaking a command or accepting an offer. The rhetorical relation of 'motivation' is used to link the nucleus to a satellite that provides information that is likely to increase the addressee's willingness to respond favourably to the proposal. And the rhetorical relation of 'enablement' is used to link the nucleus to a satellite that provides information that is likely to increase the addressee's ability to respond favourably to the proposal.

\section{Contextual and semantic organization of the factorial explanation}

Having sketched the resources of rhetorical complexing, I can now return to the analysis of Text 1 as an illustration of how elements of contextual structure are realized semantically.

The first contextual element, Phenomenon Identification, is realized by a rhetorical complex that serves as the nucleus of the whole text, [1] - [2] - text segments [1] and [2] being linked by the rhetorical relation of 'elaboration'. This nucleus is elaborated by the remainder of the text, [3] - [18]. The nucleus of the whole text defines the phenomenon to be explained, physical weathering, and it provides a generalization about the causes of physical weathering:

[1] This process is the cause of the breaking-up of large rocks into smaller pieces.

[2] Physical processes can cause changes in rocks.

That is, physical processes break up large rocks into smaller pieces.

The second contextual element, Factors, is realized by the satellite segment that is linked to the global nucleus ([1] - [2]) through the rhetorical relation of 'elaboration'; this satellite spans [3] through [18] and provides an elaboration of 'physical processes'. This elaboration is segmented by a multi-nuclear relation of 'addition' into two spans, differentiated in terms of the importance of the causal factors. Each of these spans is introduced by a nuclear segment, followed by an elaborating satellite:

[3] The two most important methods are changes in temperature and the freeze-thaw changes of water. <elaboration> [4] - [7] 
[8] There are also four other processes that are important to the breakdown of rocks. <elaboration> [8] - [18]

The nuclear segments thus serve to impose organization on the five factors that may be involved in physical weathering; that is, the factors are not presented as a "flat list" - they are presented with internal organization by means of rhetorical complexing. This is why I suggested a slight revision of Veel's (1997: 180-181) analysis of the contextual structure of the factorial explanation.

By exploring the semantic patterns of elements of contextual structure as I have just done for Text 1 , we can begin to identify the semantic strategies that are used in different text types operating in different situation types. For contexts where the field of activity is that of explaining a phenomenon by reference to factors that may cause it, we can tentatively suggest that the semantic strategy is to realize the Phenomenon Identification element of the contextual structure as the nucleus of the explanatory text, and the Factors element as an elaborating satellite supporting this nucleus: see Figure 9.

The realizations shown in Figure 9 are stated in terms of rhetorical complexes. Here the tactic distinction between "nucleus" and "satellite" makes it possible to capture Hasan (1984) distinction between "nuclear" and "elaborative" meanings in the realization of generic elements (for a more detailed discussion, see Matthiessen 2014). By "pruning" satellites in Text 1, we can produce an abridged version of this factorial explanation; for example:

Text 2: Abridged version of Text 1, Physical Weathering

Physical Weathering

[1] This process is the cause of the breaking-up of large rocks into smaller pieces.

[2] Physical processes can cause changes in rocks.

[3] The two most important methods are changes in temperature and the freeze-thaw changes of water.

[8] There are also four other processes that are important to the breakdown of rocks.

To improve on this abridged version, we could elaborate on [8], listing the four other processes:

[8] There are also four other processes that are important to the breakdown of rocks; these processes involve lightening, plants, animals and people.

It is, of course, also possible to imagine an expanded version of Text 1 . The general point is simply that the realization of the contextual structure of a situation by semantics is elastic like an accordion, ranging from a minimally expanded text with to a greatly expanded version of it.

As children go through the school system and face the task of producing texts in situation types that are new to them (or at least new to them in the institution of structured education), they tend to start with minimal texts, as illustrated by the report on dolphins in Figure 10 (for this text, see also Matthiessen, Slade and Macken 1992), and then they gradually learn how to expand these minimal texts, putting more semantic flesh on the rhetorical bones, as it were. 
Figure 10 Semantic realization of elements of generic structure stated in terms of logico-semantic relations. 
When we explore the semantic realization of contextual structures by means of rhetorical-relational complexes along the lines suggested here and illustrated by reference to Text 1 (see the analysis in Figure 8), it becomes possible to adjust the division of descriptive labour between context and semantics. For example, it would seem that in the contextual description of factorial explanations, it makes sense to posit one element following the Phenomenon Identification - viz. Factors; but it is less helpful to treat this element as "recursive" at the level of context since the identification of causal factors may in fact involve rhetorical complexing with internal nesting at the level of semantics, as in our example in Text 1 . Semantically, the causal factors may be organized into groups, as they are in Text $1-$ the two most important factors plus four additional factors.

The rhetorical complexes that realize elements of the contextual structure are, in turn, realized lexicogrammatically, at the stratum below semantics (cf. Matthiessen 1995a, 2002). They are realized congruently either by cohesive sequences of structurally unrelated clauses or by clause complexes of tactically related clauses. Longer passages tend to rely on cohesion, as in the additive sequence in Text 1 :

[8] There are also four other processes that are important to the breakdown of rocks.

[9.1] Firstly, rocks may be shattered by lightning [...]

[11.1] Secondly, plants assist the breakdown of rocks [...]

[14] Thirdly, animals' burrows often loosen and mix soil and rock pieces. [...]

[16] Finally, the actions of people cannot be forgotten. [...]

Clause complexing takes over more locally in the rhetorical-relational organization of text; local rhetorical complexes are more likely to be realized by clause complexes, as in:

[7.1] If water is trapped in a crack in a rock [7.2] and then freezes, [7.3] it can force that crack to widen.

However, rhetorical complexes may also be realized incongruently (e.g. Matthiessen 1995a, 2002). In this metaphoric mode of realization, the point of realization of a rhetorical complex is, as it were, pushed down in the grammar from clause complex to clause, or even further down to phrase or group. For example, we can analyse [4] in Text 1 as a metaphoric rendering of a causal rhetorical complex, 'because the temperature changes, the rock expands and shrinks'. The realization of this rhetorical complex is downgraded from clause complex to clause, as shown in Figure 11; in other words, the realization is incongruent:

[4] Changes in temperature cause the rock to expand and shrink.

Here the causal part of the rhetorical complex is realized not as a clause (the temperature changes) but as a nominal group with a nominalized verb as Head (changes in temperature) serving as Agent in a 'material' clause with a causative verbal group complex as Process, cause ... to expand and shrink.

Over the years, the practise in RST analysis came to be to stop the analysis at ranking clauses since, in the congruent mode of realization, they realize figures (experiential) 


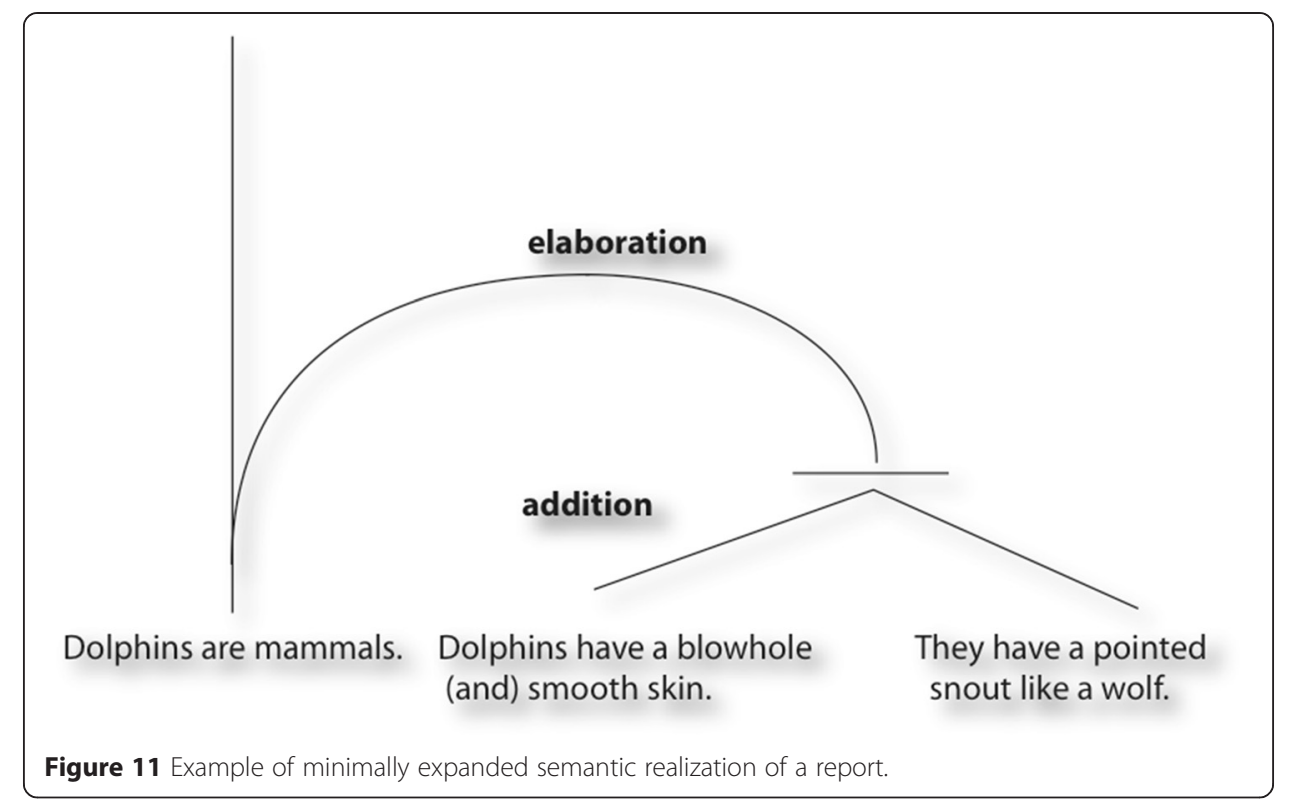

that are also propositions or proposals (interpersonal) and messages (textual); see Halliday \& Matthiessen (2004: 589). However, wherever grammatical metaphors occur in texts, it makes sense to extend the analysis of rhetorical complexes further down, descending below ranking clauses, so that incongruent patterns of realization can be brought out. In the extract from a text explaining monsoons in Text 3, there are several instances of incongruent realizations of rhetorical complexes, a number of which involve a causal relation realized incongruently by a verb (shown in bold in the passage) - cause, result in, lead to. For example, the following passage includes a causal sequence of figures:

In summer, intense solar heating leads to scorching temperatures over the Asian land masses. As a result, the overlying air heats up, expands and rises upwards. This leads to the formation of a semi-permanent low pressure area near the heart of the continent.

The passage is analysed in terms of rhetorical complexes in Figure 12, where semantic glosses are shown together with the incongruent lexicogrammatical realizations. The last clause of the passage includes the nominalization the formation of a semipermanent low pressure area near the heart of the continent, which is an incongruent realization of a figure. This nominalization serves as a participant in a circumstantial relational clause where the Process is a "verbalization" of a conjunctive relation ('so'), viz. leads to; this relational clause is an example of a common metaphoric rendering of the relation of 'cause'. A more congruent version of this passage would be:

As a result, the overlying air heats up, expands and rises upwards, so a semipermanent low pressure area forms near the heart of the continent.

The extent to which registerial complexes are realized congruently or incongruently is subject to considerable variation across registers, so it is important to take account of the degree of metaphorical patterns in realization as part of our registerial 


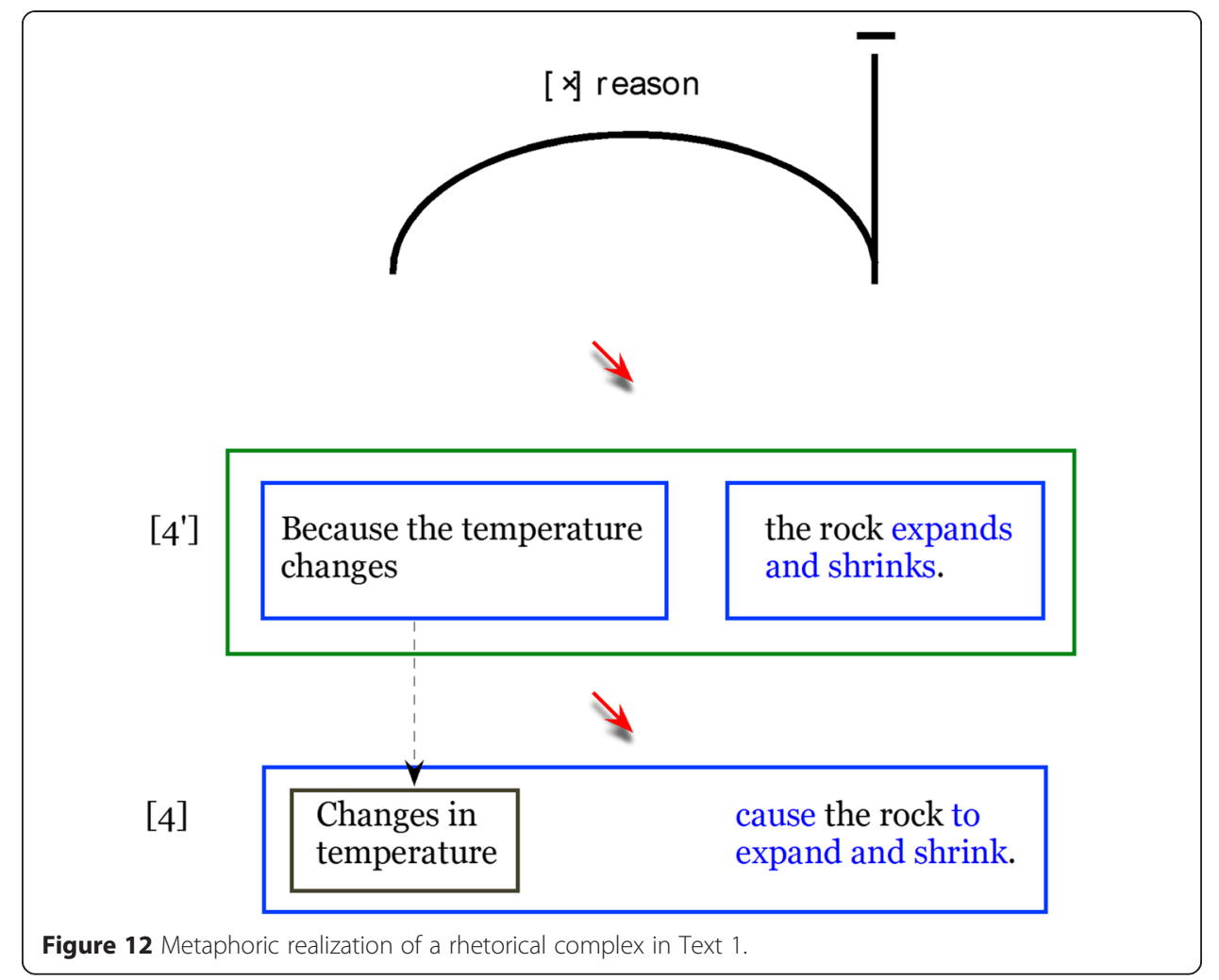

cartography. The division of labour between these two modes of realization depends on all three contextual variables - field, tenor and mode.

The distinction in mode between spoken and written medium has been shown to be important - as part of the general difference between speech and writing: see Halliday $(1985,1987)$ and, with reference to the realization of rhetorical complexes, Matthiessen (2002). In prototypical spoken language, rhetorical complexes tend to be realized congruently - cohesively and tactically (i.e. by clause complexes), whereas in prototypical written language, rhetorical complexes tend also be to realized incongruently - by clauses and their component parts, as illustrated above.

Distinctions in tenor are also significant: texts that deploy the metaphoric mode of realization to a high degree tend to be produced $\boldsymbol{b y}$ experts for experts, and it was in the discourses of science between experts that grammatical metaphor evolved in English over a period of half a millennium or so (see Halliday 1988). Here there is also a developmental dimension (see e.g. Halliday and Matthiessen 2006: Ch. 6): as learners move from primary school to secondary school, and perhaps on to university and engage with increasingly "academic" texts, they have to master increasingly metaphorical modes of meaning, as shown by Christie and Derewianka (2008).

At the same time, distinctions in field are also relevant. The examples I have quoted all come from texts operating in 'expounding' contexts (Figure 5). Such contexts favour the metaphorical mode of construing experience because this mode facilitates the construction of theory. Halliday (1988) found that such passages in Newton's Opticks had more instances of grammatical metaphor than passages where he provided recounts of his experiments - such texts being located within 'reporting' rather than 'expounding' contexts. Grammatical metaphor is, of course, found in texts operating in contexts 
defined by other fields of activity - they are favoured in 'elaborating' contexts, for example; but they are deployed in different ways, and some contexts seem to favour the congruent more of construal, as is the case with 'instructional' contexts (within the 'enabling' sector of Figure 5).

Text 3: Extract from causal explanation of monsoons ${ }^{\mathrm{i}}$

Monsoons

Monsoons are large-scale wind systems caused by differences in the temperatures of land and sea over the seasons.

In winter, the continental land mass cools off rapidly, resulting in very low temperatures over central Asia. As cold air accumulates, pressure rises and a huge continental anticyclone develops over Siberia with the Tibetan Plateau forming an effective barrier blocking the southward spread of cold air from the anticyclone. From time to time, under the influence of upper air disturbances, cold air from this anticyclone plunges southward through China and brings outbursts of cold air to the south China coastal areas. Depending on the time of the season, and the juxtaposition of various weather systems, these surges will arrive in Hong Kong as northerlies, northeasterlies or easterlies.

In summer, intense solar heating leads to scorching temperatures over the Asian land masses. As a result, the overlying air heats up, expands and rises upwards. This leads to the formation of a semi-permanent low pressure area near the heart of the continent. Warm and moist air from the Indian Ocean and the South China Sea flowing into this low pressure area is experienced as the summer monsoon over south and southeast Asia.

\section{Registerial cartography: fields of activity and types of rhetorical relation}

In the previous section, I illustrated how registerial cartography can be extended to include patterns of semantic realization - semantic strategies deployed in the realization of different situation types. I focussed on ideational strategies because my starting point was field of activity within context; and within ideational strategies, I focussed on logical ones - on the deployment of rhetorical-relational complexing to organize a text as it unfolds within its context of situation, stage by stage. Naturally, the account has to be extended to cover not only field of activity within context but also field of experience ("subject matter"), tenor and mode; and to cover the full metafunctional spectrum of semantic resources. But let me continue to explore registerial cartography with a focus on field of activity and logical resources - rhetorical-relational complexing.

\section{Beyond 'expounding' examples}

The examples in the previous section were all from the 'expounding' sector of Figure 5, beginning with the factorial explanation in Text 1: see Figure 13. To pursue the research programme of registerial cartography (cf. Figure 2 above), we need to identify fields of activity at tertiary degree of delicacy, describe the situation types that they define by specifying the contextual structure of each situation type, and describe the patterns of the semantic realization of each situation type by specifying the characteristic rhetorical-relational structure. This research programme is, of course, a very large-scale long-term undertaking. I have been exploring different regions of the map in Figure 13, but even though the coverage is still only a modest sample, it would take a book-length 


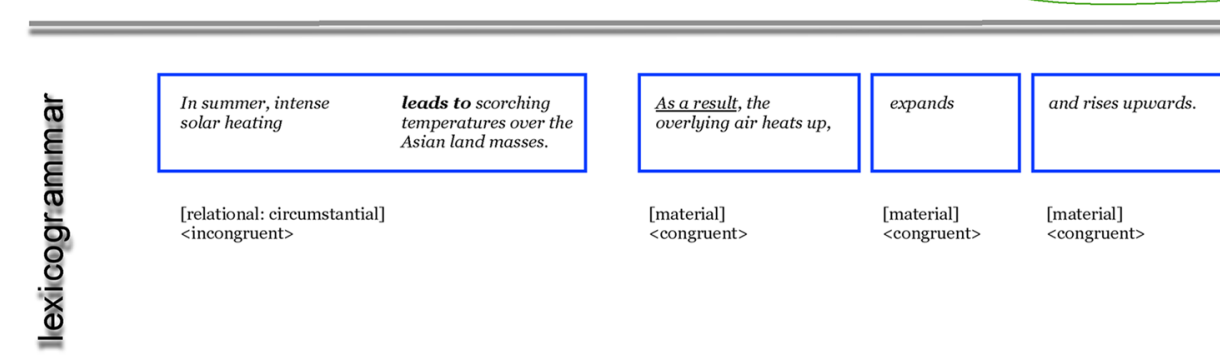

[x] reason

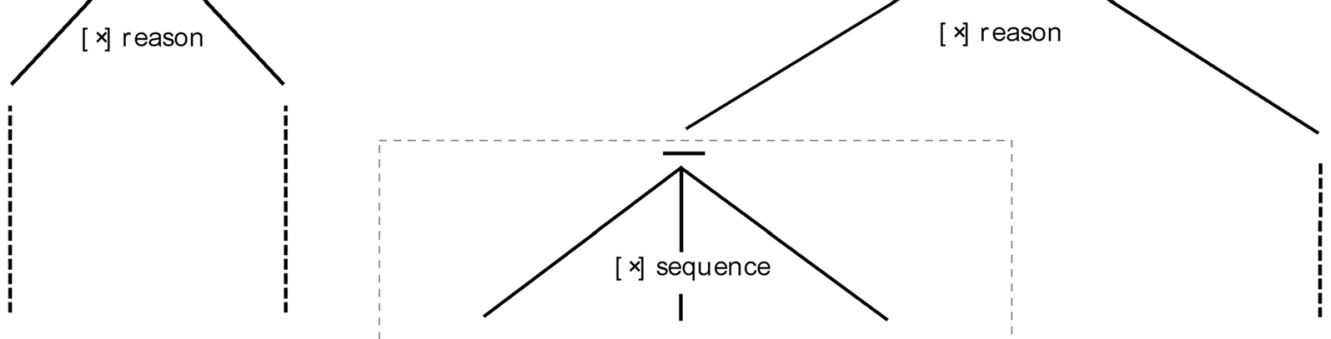

'in summer, sun ' 'temperatures $\quad$ 'air heats up' $\quad$ 'it expands' $\quad$ 'it rises upwards' $\quad$ 'low pressure forms' intensely'

'low pressure forms'

Figure 13 Metaphoric realization of a rhetorical complex in Text 3. 
publication to present the all findings, so all I can do here is select a few examples that I hope will indicate the nature of the work.

Let me begin by selecting four of the eight primary fields of activity, viz. 'expounding', 'reporting', 'recommending', and 'exploring with one or two representative text types for each of them:

- expounding: explanation, report

- reporting: news article (report)

- recommending: advertisement

- exploring: review, exposition

The situation types in which these text types operate all have different contextual structures, as can be seen from the accounts in Eggins and Slade (2005) and Martin and Rose (2008). These different contextual structures are reflected in semantic differences - in different preferences for rhetorical relations in the organization of texts into rhetorical complexes.

\section{View "from below": local rhetorical complexes}

Let me begin by illustrating this point by reference to logico-semantic relations in clause complexes that realize "local" rhetorical complexes. It turns out - not surprisingly - that different types of socio-semiotic process within field favour different types of logicosemantic relation, as shown in Figure 14. While 'enhancing' relations are the most common in all text types except for "casual chat", the division of labour among the logico-semantic relations differs from one text type to another. 'Enhancing' relations play the most prominent role in those text types where temporal sequence is the primary organizing principle i.e. stories and procedures. (Of course, 'enhancing' relations cover not only temporal relations but also other types of circumstantial relation). In contrast, in news reports, they are almost overtaken by 'projecting' relations of the subtype 'locution' reflecting the need in the media to provide the source of information by quoting and reporting people (sometimes called "attribution"). Since modern news reports are no longer temporally organized news stories (cf. Nanri 1993; Iedema, Feez and White 1994), 'enhancing' relations are relatively much less common than in stories - in contrast with 'elaborating' relations: the same news item tends to get elaborated again and again in a modern news report, from different vantage points.

The picture that emerges from Figure 14 is merely an illustration of what can be expected from further research. It certainly needs to be supplemented by counts of selections of rhetorical relations at the level of semantics - relations ranging in scope from whole texts, global relations, to local rhetorical complexes. Producing such counts based on the texts that have been analysed in terms of RST is part of my research agenda; but, for now, I will change gears, and just give a few analyses of texts that I think can serve as exemplars of the text types they belong to. These examples can be compared and contrasted with the analysis of the factorial explanation in Figure 7 above. In comparing and contrasting the examples sampled from different contexts, I will be concerned with a number of questions, including:

- Is the global organization of the text being analysed as a rhetorical complex primarily multi-nuclear or mono-nuclear - that is, is the text organized around a single nucleus, as factorial explanations are (illustrated by Text 1 ), or is organized as a sequence of nuclei? 


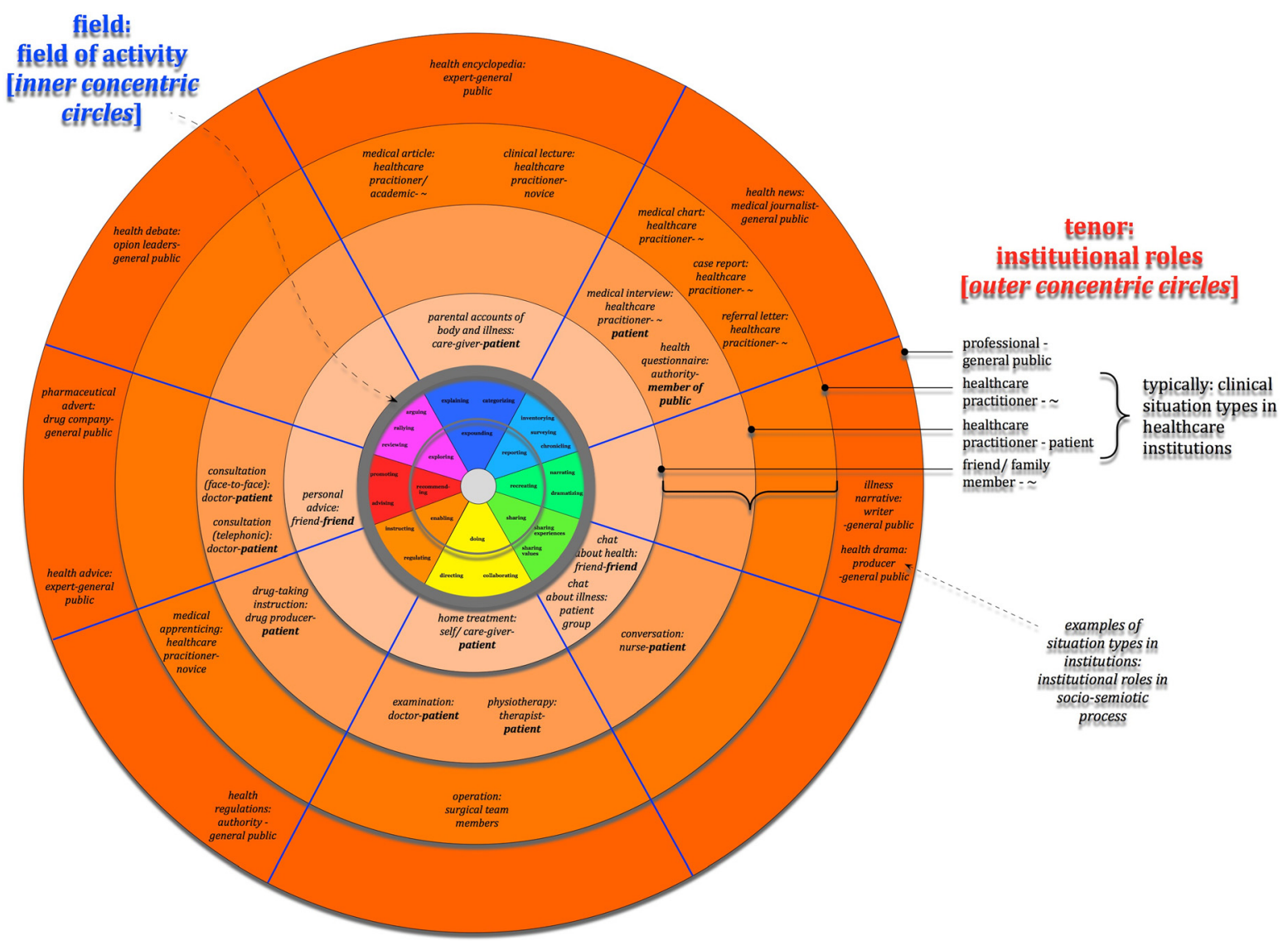

Figure 14 Explaining by reference to causal factors - location within the overall map of fields of activity (cf. Figure 5). 
- If the global organization of the text is mono-nuclear, is the nucleus given the status of macro-Theme, macro-New or neither?

- Is the global organization of the text dominated by 'internal' relations such as 'evidence' and 'motivation' or by 'external' ones such as 'elaboration' and '(temporal) sequence'?

I will address these questions either as I present the analyses of different types of text or as I summarize the sample analyses.

\section{Additional 'expounding' example: a sequential explanation}

Before we move out of 'expounding' contexts, I will give one more example of an explanation - this time a 'sequential' explanation rather than a 'factorial' one. The semantic analysis in terms of rhetorical-relational complexing is set out in Figure 15. In terms of the contextual structure, the Phenomenon Identification is really only realized by the title of the text, [0] The Refining Process; the remainder of the text is devoted to the explanation. This explanation is a temporal sequence of the operations that make up the refining process, starting with [1] In an oil refinery, petroleum is first heated in a furnace to about $400{ }^{\circ} \mathrm{C}$. In other words, while the 'factorial' explanation analysed in Figure 7 is organized globally as a nucleus-satellite complex, this 'sequential' explanation is dominated by a multi-nuclear complex. For a more detailed discussion of this text (including the intersemiotic relations between text and image), see Matthiessen and Pun (forthcoming).

\section{'Reporting': a news report}

Moving clockwise from 'expounding' contexts in Figure 5 above, we can consider texts operating in 'reporting' contexts. Historical recounts (see e.g. Coffin, 2006; Christie and Derewianka 2008; Martin and Rose 2008) resemble sequential explanations in that they are organized globally as temporal sequences. However, while sequential explanations

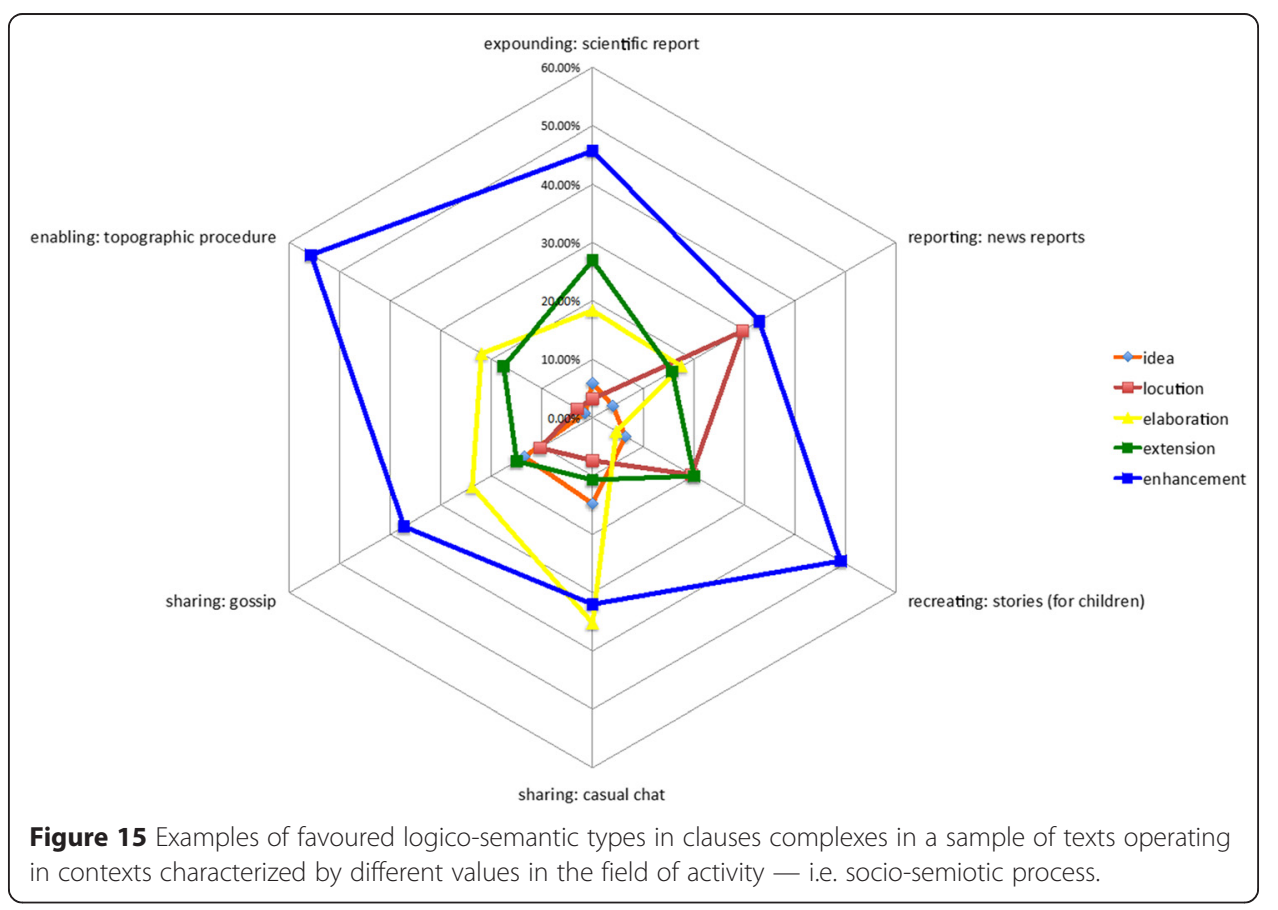


are concerned with general classes of events (like the refining process), historical recounts are concerned with particular events. I will instead focus on news reports; like historical recounts, they belong to the 'chronicling' type of 'reporting' but they have evolved to become very different from the "news stories" that they developed out of (see Nanri 1993; Iedema, Feez and White 1994): see Text 4.

Text 4: Example of a news report operating in a reporting: chronicling context ${ }^{j}$

[0] ||| [0.1] Two Australians missing || [0.2] as storm sinks Thai ferry |||

[1] ||| [1.1] Two Australian women are among 20 people [[feared dead]] || [1.2] after a ferry sank off the coast of Thailand. III

[2] III [2.1] Naomi Mary Leslie, 24, of Perth, and Grabrielle Sandercock, 33, reportedly from Melbourne, were on board the ferry || [2.2] when it overturned on its way to the island of Koh Tao on Wednesday. |||

[3] ||| [3.1] Witnesses claim || [3.2] the ferry's Thai captain ignored warnings [[[against trying to press ahead through a violent storm $\|$ after leaving the mainland town of Surat Thani late on Tuesday night for the seven-hour voyage]]]. |II

[4] II| [4.1] Several of the 18 survivors said || [4.2] the vessel, $<<$ [4.3] which appeared to be overloaded,>> lacked life vests and other safety equipment. |||

[5] ||| [5.1] "In less than one minute, everything was gone", || [5.2] survivor Somsak

Thongtraipop told Thailand's The Nation newspaper. |||

[6] III He had heard [[[the captain on the radio being warned by a crew member from another boat || that there were big waves ahead || and he should turn back]]]. |||

[7] ||| [7.1] He and seven others survived || [7.2] by clinging to a floating fish container for hours.|||

[8] ||| [8.1] "Big waves, three to four metres high, lashed us all the time," || [8.2] Mr Somsak said. ||| [9] ||| "It was like we were in hell." |||

[10] ||| [10.1] Many of those [[who died]] were trapped || [10.2] when water gushed into the boat's cabin. |||

For the description of the contextual structure of such "hard news" reports, see e.g. Iedema, Feez and White (1994) and Martin and Rose (2008: 74-81): Headline ${ }^{\wedge}$ Lead ${ }^{\wedge}$ Lead Development (^ Wrap-up). The contextual analysis of Text 4 is given together with the semantic analysis of the rhetorical complexing of the text and the grammatical analysis of clause complexing in Figure 15. The Lead is realized by the global nucleus of the text as a rhetorical complex; and this nucleus could serve as a summary of the whole text - a minimal news report. Both the Headline and the Lead Development can be analysed as supporting satellites linked by elaborating relations, restatement and elaboration, respectively (for the inventory of relations, see Figure 8 above). The text segment realizing the Headline provides a short restatement of the text segment serving as the Lead, whereas the text segment serving as the Lead Development provides a much more detailed elaboration and another more local elaboration. The expanded elaboration is organized as an 'additive' rhetorical complex, each segment in this additive series providing a different angle on the maritime disaster - in two main segments: survivors and eyewitnesses, and casualties.

Globally, news reports tend to be dominated by 'elaborating' relations (restatement, elaboration) and 'extending' ones (addition) rather than by 'enhancing' ones. The latter are deployed to organize news reports more locally in terms of time (the sequences of 
events), as with the temporal circumstantial relations in Figure 15. Here the news report cycles through the same sequence of events a number of times: see Tables 1 and 2 .

In the realization of the Lead Development, the more local rhetorical organization is dominated by 'projection' - in the case of this text, quotes and reports from eyewitnesses; in other news reports, we may also find quotes and reports from public professionals like the police and rescue workers, other experts and "VIPs".

\section{'Recommending': an advertisement}

Continuing to move clockwise around in Figure 5 above, I will now move from 'reporting' contexts to 'recommending' ones, skipping several segments of the figure. Within 'recommending' contexts, there are two distinct fields of activity - advising and promoting. Advising means recommending some course of action (e.g. medical treatment, financial investment) with the addressee as the beneficiary (at least ostensibly!), whereas promoting means recommending some course of action (e.g. buying a medical product, subscribing to a health service) with the speaker as the beneficiary. The two types obviously shade into one another; for example, pharmaceutical companies produce advertisements that appear to be expert advice.

Let me give a very short example of an advertisement, one promoting Korean Airways (from the 1980s): see Text 5.

Text 5: Example of a text in promoting recommending context - an advertisement

[1] Our Korean spirit is moving in the air. [2] It's a spirit of untiring, ceaseless effort and ageless charm that flows from Korean traditions perfected over thousands of years. A spirit of advancing into the future with one of the world's most modern fleets. And a spirit that soars around the globe to 44 cities in 21 countries on 5 continents. [3.1] Fly with us [3.2] and you'll experience the dedication to excellence that could only be Korean.

Even though the text is very short, the rhetorical complex analysis brings out some recurrent key features we find in such texts: see Figure 16. Advertisements tend to be organized around a nuclear proposal - in terms of the contextual structure, this is the Appeal $^{\mathrm{k}}$. The nuclear proposal is either a command or an offer; but the important point is that it is an exchange of goods-\&-services. This nuclear proposal is supported by satellite segments that motivate or enable the addressee to undertake the command or accept the offer. In the case of the Korean Air advertisement, the nuclear proposal is the command [3.1] Fly with us. This proposal is supported locally by [3.2], which spells out the positive consequence of flying with the airline. It is also supported more globally by [1] and [2], which like [3.2] are satellites giving positive information about Korean Air.

While both the factorial explanation analysed in Figure 8 and the news report analysed in Figure 17 are texts organized as expansions of a central nuclear segment (unlike the sequential explanation in Figure 18) and the Korean Air text is similar in this respect, there is a fundamental difference. The expansions of the factorial explanation and of the news report are external in orientation - both texts are concerned with "building field" (cf. Martin 1993, for the notion of building field). In contrast, the expansions of the global nucleus of the Korean Air advertisement are internal in orientation: both of them are the internal relation of 'motivation' - the text is not primarily 


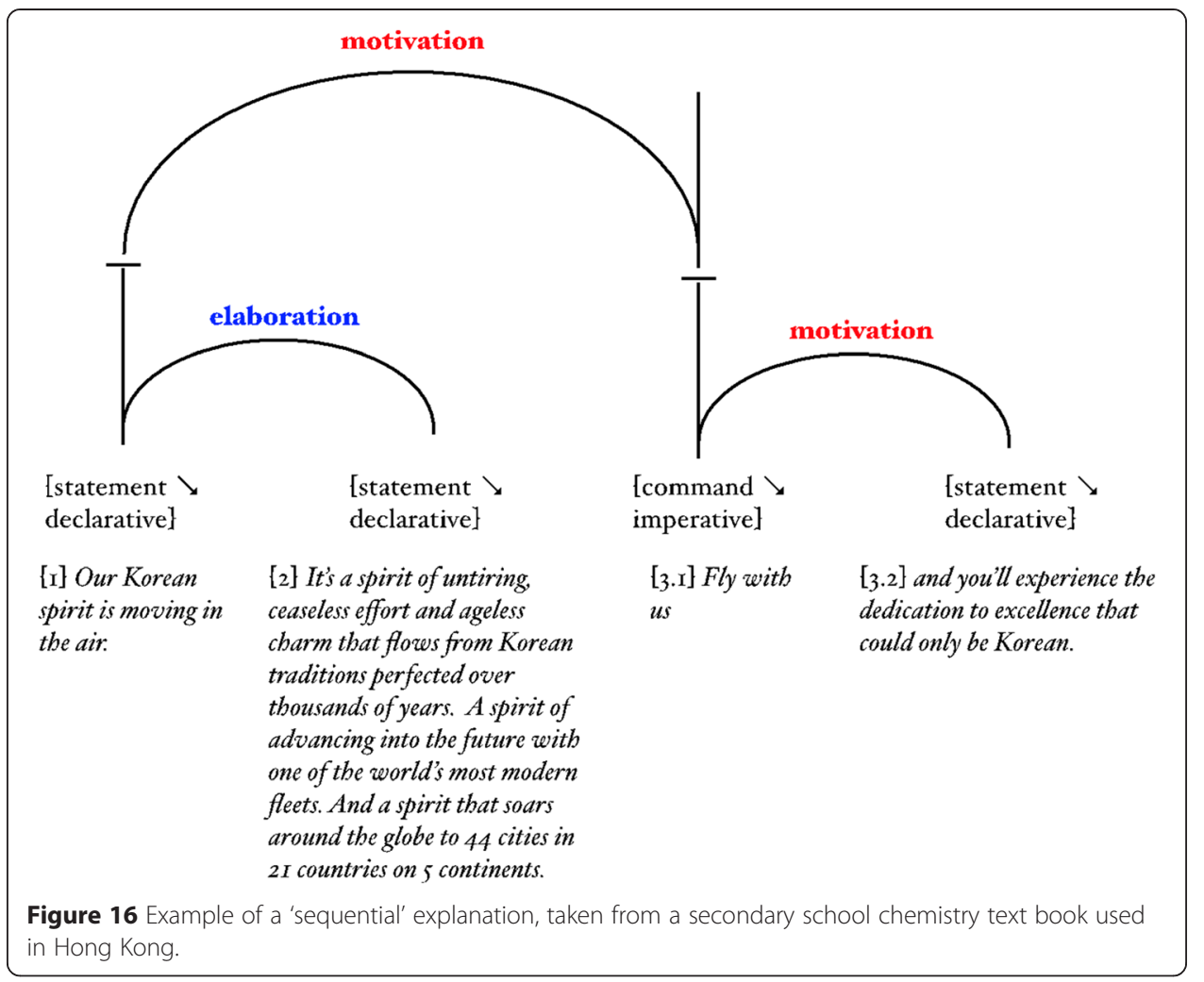

concerned with building field but rather with negotiating tenor (cf. Halliday, 2001, on different metafunctional orientations in the organization of text), moving the addressee closer to the position where "Korean Air" would like him or her to be - a characteristic feature of various kinds of persuasive text. Like internal relations in general, they link supporting satellites to a nucleus, thereby increasing the likelihood of the success of the nuclear speech function in terms of the addressee's response (cf. Mann and Matthiessen 1991). The satellites build value - positive value attributed to Korean Air.

\section{'Exploring': a review}

Having briefly considered a text operating in a 'recommending' context of the 'promoting' subtype, let's now move clockwise again to the next segment, that of 'exploring' contexts. Just as other primary fields of activity cover a considerable range of activities that must be differentiated when we increase the delicacy of descriptions, so does the activity of 'exploring' prototypically public values, ideas and positions. There seem to be two primary kinds of exploring - reviewing and arguing. Arguing contexts have been illuminated by researchers in educational linguistics - see e.g. Coffin (2006), Christie and Derewianka (2008) and Martin and Rose (2008). The analysis of such arguing texts in terms of rhetorical complexing shows that they are organized around a nuclear proposition - one where a claim is made, which is supported by a satellite providing evidence for this proposition. However, let me give an example of the analysis of a text operating in a 'reviewing' context: see Text 6 .

Text 6: Example of a product review, operating in an 'exploring' context - user review an HP printer ${ }^{1}$

This printer absolutely stinks. Mine has not worked for 8 months and I havent even begun to try and fix it because last time it happened it took me forever to fix and I 


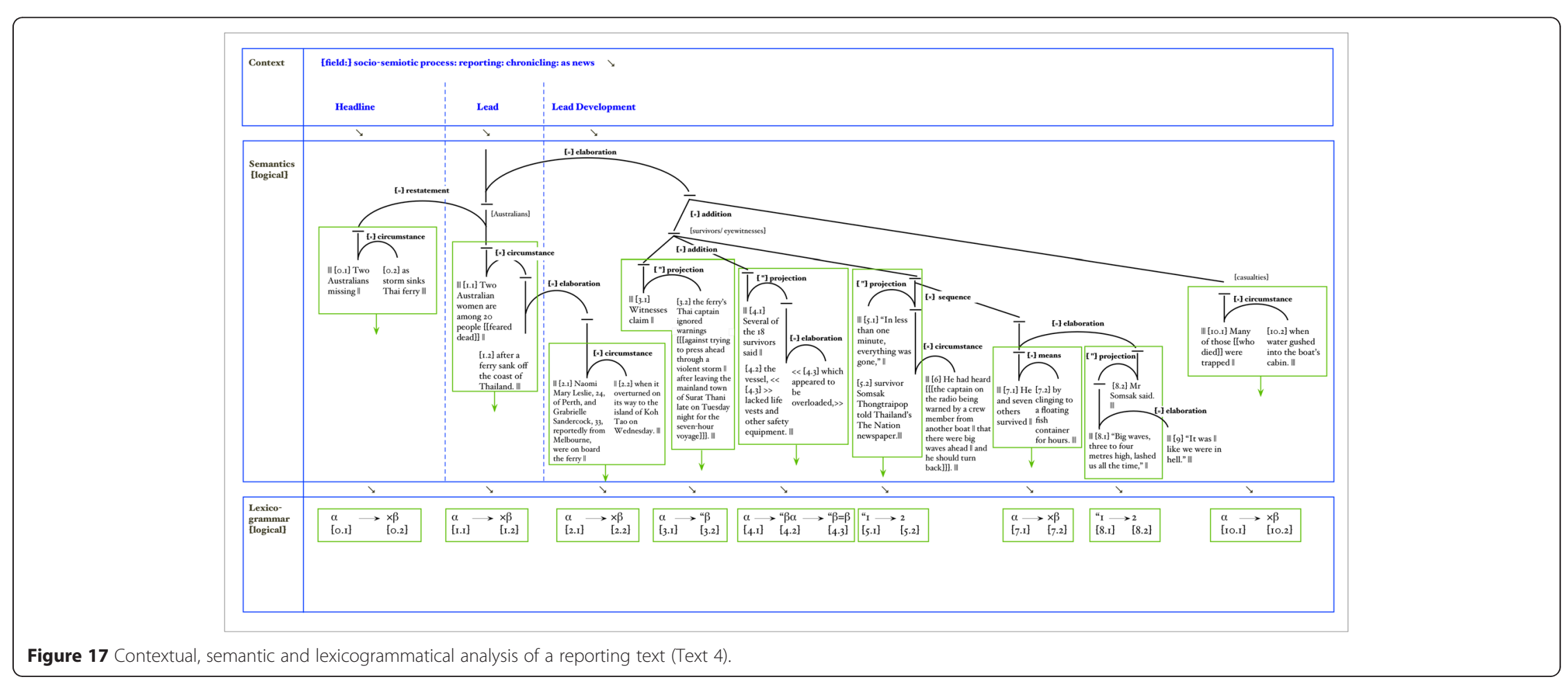




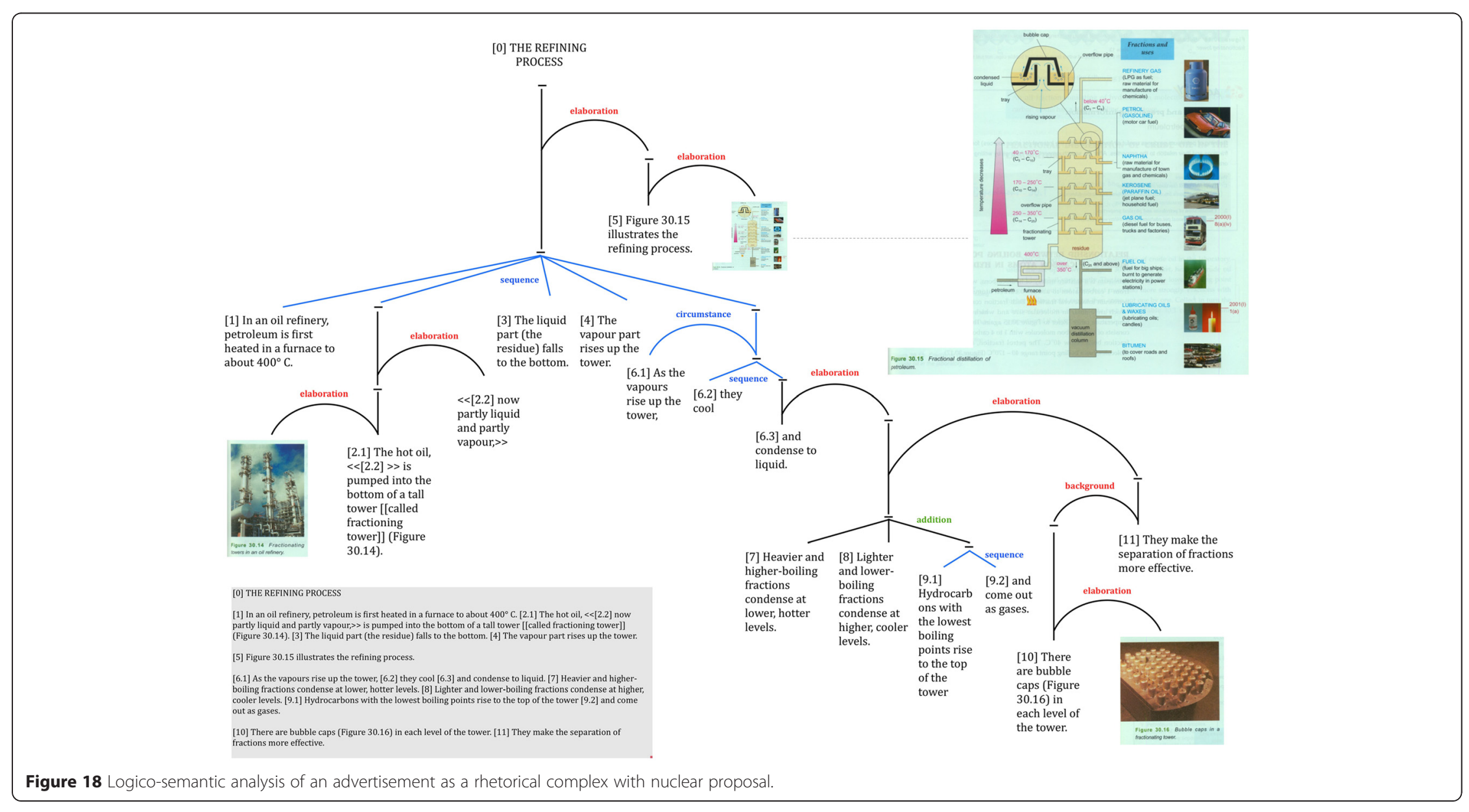


don't have that kind of time on my hand with school (which a broken computer does not help me with at all). Both of my roommates have the same printer and neither of theirs are working. Three of the same printer in one apartment, but we still don't have a printer. Mine is "Not responding" And my roommates are "Offline".

This text is organized around a key nucleus, This printer absolutely stinks: see Figure 19. This is a proposition rather than a proposal; more specifically, it is a statement, realized by a declarative clause. The statement is interpersonally highly loaded a highly negative assessment of the product under review, referred to as this printer. In terms of the description of the resources of interpersonal system of appraisal presented in Martin and White (2005), absolutely realizes raised gradation, and stinks realizes negative judgement. Grammatically, this is achieved by means of an intensive attributive relational clause - one of the grammatical strategies for assigning assessments; normally, the configuration would be Carrier + Process + Attribute, but this clause represents an alternative where the Attribute and the Process are as it were fused: Carrier: this printer + Process/ Attribute: stinks - reinforced by absolutely, which can be analysed as a circumstance of Manner: degree (although absolutely can also function interpersonally as a mood Adjunct of high degree).

The nucleus of the product review, Text 6 , is thus a highly negatively loaded statement about the product under review. The remainder of the text serves as a satellite supporting this negative claim, linked to it by a rhetorical relation of 'evidence'; and negative evaluations extend as a prosody throughout the whole satellite segment. The satellite is organized as a multi-nuclear rhetorical complex of addition: the first part of the evidence is the reviewer's own experience, and the second part refers to his

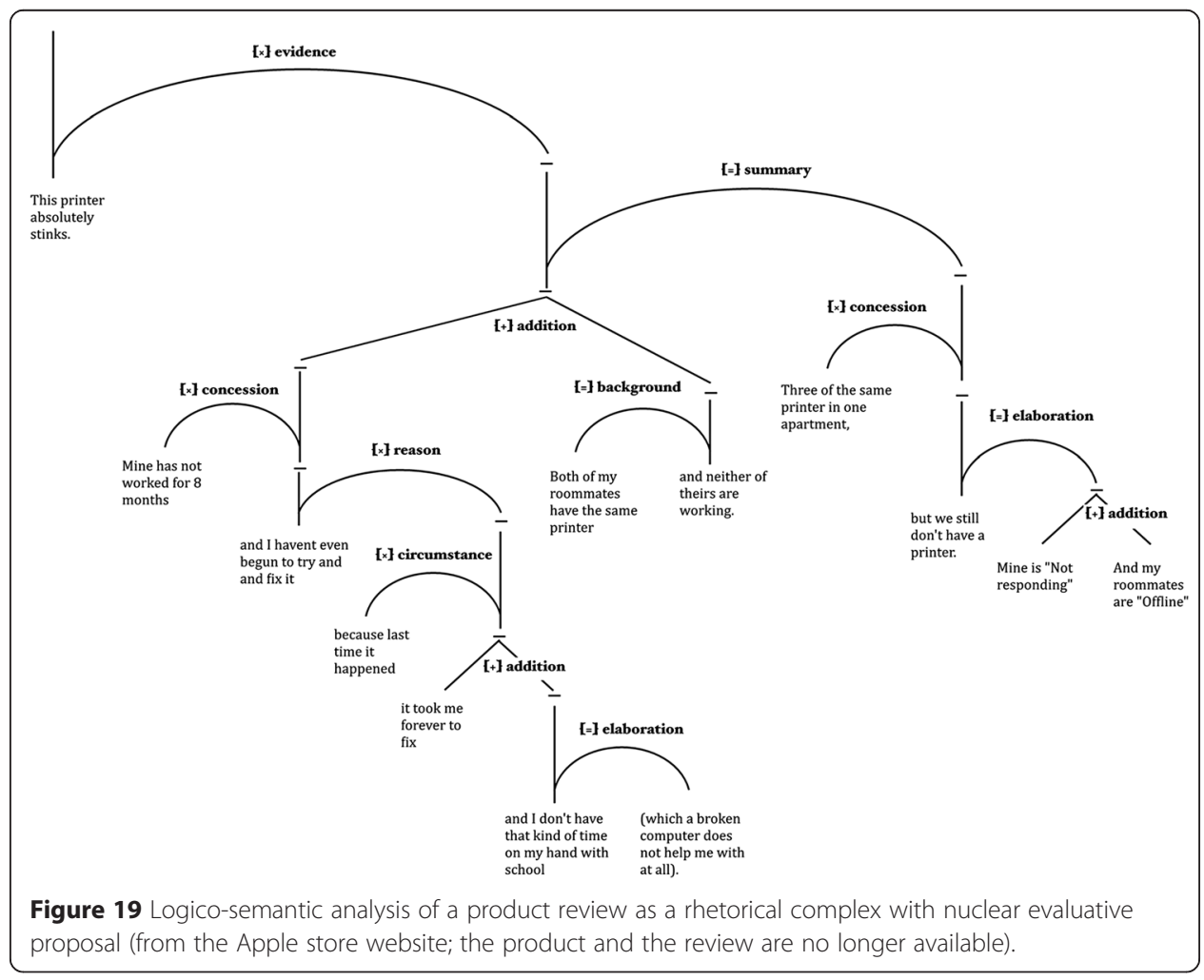


roommates' experience. This rhetorical complex is then summarized in the last segment of the text. The rhetorical relation of 'evidence' is thus involved in the global organization of the text. It is 'internal' in orientation rather than 'external' (see the inventory of relations in Figure 9 above); that is, it serves to link a satellite text segment to the nucleus that is likely to increase the success of the speech function of the nucleus in this case, the likelihood that the reader will believe that the printer is really bad.

Text 6 clearly operates within an 'exploring' context - more specifically 'reviewing' (rather than 'arguing'): like reviewing texts in general, it allocates value to a commodity in a public forum. Until fairly recently, reviews could be expected to be produced by professional reviewers working for traditional media such as print news papers. However, with technological developments dramatically changing the nature of "channel" within mode, there has been a blurring between what's public - traditionally negotiated in 'exploring' contexts, and what's private - traditionally negotiated in 'sharing' contexts (see e.g. Macnamara 2010; Shirky 2010). Thus Text 6 seems, in certain ways, like the kind of text that would unfold as casual conversation among friends in a 'sharing' context - and this is a feature of many user reviews that appear in many places around the World Wide Web. In a sense, such texts can be interpret as instances of registerial hybridity (cf. Matthiessen \& Teruya 2015).

Like Text 5, Text 6 is organized around a nucleus, and the bulk of the text is a satellite related to the nucleus by an 'internal' rhetorical relation, the relation of 'evidence'. Thus both texts are organized globally in terms of 'internal' rather than 'external' relations, in contrast with Text 1 (expounding: explaining: factorial explanation), Text 3 (expounding: explaining: sequential explanation) and Text 4 (reporting: chronicling: news report). The organization of texts globally as rhetorical complexes involving internal relations such as motivation and evidence is characteristic of contexts where the interactants negotiate tenor (rather than build field) - broadly speaking, contexts where speakers or writers try to persuade their addressees to do something, a recommending context (as in Text 5), or to believe something, an exploring context (as in Text 6). Of course recommending and exploring shade into one another. A positive review of a product can have some of the same effect as an advertisement for it; and positive reviews may be quoted as part of the promotion of a product (as on film posters). And in particular user reviews of products may come with a strong recommendation; for example, in a review of the last film by Akira Kurosawa, Madadayo, a contributor to the IMDB "user review" section writes:

don't make the same mistake i did. don't put off seeing this movie. whether you're a fan of his work or not, you're guaranteed to enjoy it. it's the kind of films that transcend genres and leaves you touched, whether you were looking for it or not.

But there's still a principled difference between a company marketing a product and somebody else evaluating it.

\section{Nuclearity and orientation}

The texts that I have sampled from different contexts illustrate two dimensions of variation in the overall, global organization of texts as rhetorical complexes: nuclearity and orientation. These two dimensions are intersected in Table 3, where the texts discussed 
Table 3 Registerial variation in the global organization of texts as rhetorical complexes in terms of nuclearity (nucleus-satellite vs. multi-nuclear) and orientation (external vs. internal)

\begin{tabular}{|c|c|c|c|}
\hline & & nucleus-satellite & multi-nuclear \\
\hline \multirow[t]{5}{*}{ external } & \multirow[t]{2}{*}{ expounding } & $\begin{array}{l}\text { documenting: taxonomic } \\
\text { reports, descriptive reports } \\
\text { (Figure 11) }\end{array}$ & \\
\hline & & $\begin{array}{l}\text { explaining: factorial } \\
\text { explanations (Text 1, Figure } \\
8 \text { ) }\end{array}$ & $\begin{array}{l}\text { explaining: sequential } \\
\text { explanations (Figure 16), } \\
\text { causal explanations }\end{array}$ \\
\hline & reporting & $\begin{array}{l}\text { chronicling: news reports (Text } \\
\text { 4) }\end{array}$ & $\begin{array}{l}\text { reporting: chronicling: } \\
\text { historical recounts }\end{array}$ \\
\hline & recreating & & narrating: nursery tales \\
\hline & enabling & & instructing: procedures \\
\hline \multirow[t]{4}{*}{ internal } & recommending & $\begin{array}{l}\text { promoting: advertisements } \\
\text { (Text 5, Figure 18) }\end{array}$ & \\
\hline & & nucleus-satellite & multi-nuclear \\
\hline & \multirow[t]{2}{*}{ exploring } & $\begin{array}{l}\text { reviewing: reviews (Text 6, } \\
\text { Figure 19) }\end{array}$ & \\
\hline & & arguing: expositions & \\
\hline
\end{tabular}

here are listed together with a number of other text types. The table illustrates the registerial variation across fields of activity in the deployment of the resources of rhetorical complexing. Different fields of activity call for different organizing principles. The texts whose high-level organization is dominated by multi-nuclear complexes include those structured by relations of temporal sequence - sequential explanations, recounts, tales, and procedures. The significance of the presence or absence of temporal organization of texts has been reflected in many text typologies (e.g. Longacre 1974, 1996; Martin 1992a, 1992b; Martin and Rose 2008).

If texts are globally 'multi-nuclear', they just unfold sequentially, causally, additively, and so on. However, if texts are globally 'mono-nuclear', with a nuclear segment and a related satellite segment, the nucleus may be given a special textual status of prominence - as macro-Theme, at the beginning of the text, or as macro-New, at the end of the text (for the overall organization of text in terms of the textual metafunction, see e.g. Halliday 1981; Martin 1993), or else one or two satellites may be given textual prominence in this way. Examples of nuclear text segments as macro-Theme or as macro-New are given in Table 4.

In mono-nuclear texts operating in 'expounding' contexts, there seems to be a strong tendency for the global nucleus to be given thematic status as macro-Theme. This makes very good sense: such texts are organized so as to help speakers or writers and listeners or readers construe knowledge, and the global nucleus provides an orientation to the particular domain that a given text is concerned with - a growth point or region in this domain in relation into which new meanings can be integrated as they are constructed in the unfolding text (cf. Matthiessen 1995b). Here is a small sample of macro-thematic global nuclei in four reports: 
Table 4 Examples of textual statuses as macro-Theme or as macro-New given to the globally nuclear segments of texts

\begin{tabular}{|c|c|c|c|}
\hline & & nucleus as macro-Theme & nucleus as macro-New \\
\hline \multirow[t]{5}{*}{ external } & \multirow[t]{2}{*}{ expounding } & $\begin{array}{l}\text { documenting: taxonomic } \\
\text { reports, descriptive reports } \\
\text { (Figure 11) }\end{array}$ & \\
\hline & & $\begin{array}{l}\text { explaining: factorial } \\
\text { explanations (Text 1, Figure } \\
8 \text { ) }\end{array}$ & \\
\hline & reporting & $\begin{array}{l}\text { chronicling: news reports } \\
\text { (Text 4) }\end{array}$ & \\
\hline & recreating & & \\
\hline & enabling & & \\
\hline \multirow[t]{3}{*}{ internal } & recommending & & $\begin{array}{l}\text { promoting: advertisements [very } \\
\text { often with the appeal as macro- } \\
\text { New] }\end{array}$ \\
\hline & \multirow[t]{2}{*}{ exploring } & $\begin{array}{l}\text { reviewing: reviews (Text 6, } \\
\text { Figure 19) }\end{array}$ & $\begin{array}{l}\text { reviewing: reviews [very often } \\
\text { with "bottom line" as macro- } \\
\text { New] }\end{array}$ \\
\hline & & & arguing: expositions \\
\hline
\end{tabular}

(1) Ankylosaurs [1] The Ankylosaurs were armored lizards [[which varied greatly in size]]. [2.1] The largest was as long as a bus, [2.2] while the smallest was not much bigger than a man.

(2) The fuels of the body [1] The fuels of the body are carbohydrates, fats and proteins. [2] These are taken in the diet. [3] They are found mainly in cereal grains, vegetable oils, meat, fish and dairy products.

(3) Program [1] Programs issue instructions to the computer. [2] Many programs process files.

(4) Yangban [1] The yangban aristocracy literally meant the members of the "two orders" of officialdom [[who served in the bureaucracy as civil and military officials]]. [2.1] This elite class, $<<$ [2.2] which began to be formed toward the end of the Koryo Kingdom (918 1392), >> directed the government, economy and culture of the subsequent Chosōn Kingdom (1392 1910).

These macro-thematic global nuclei provide the points from which the meanings construed in the remainder of the texts can be expanded - typically through an elaborating satellite that constitutes the main bulk of the text.

In contrast, in mono-nuclear texts operating in 'recommending' or 'exploring' contexts, there seems to be a strong tendency for the global nucleus to be given weight as macro-New. The Korean air advertisement is too short to provide a clear example although the nuclear proposal is realized as part of the last clause complex of the text; and the review analysed in Figure 19 happens to start with the global nucleus, giving it macro-thematic status. However, advertisements often end with a macro-new punch what the addressee should take away from the text as its main point, as do reviews and also expositions. What precedes this nuclear punch serves to prepare the ground by means of a satellite related to the nucleus by 'evidence' or 'motivation'. The tendency is 


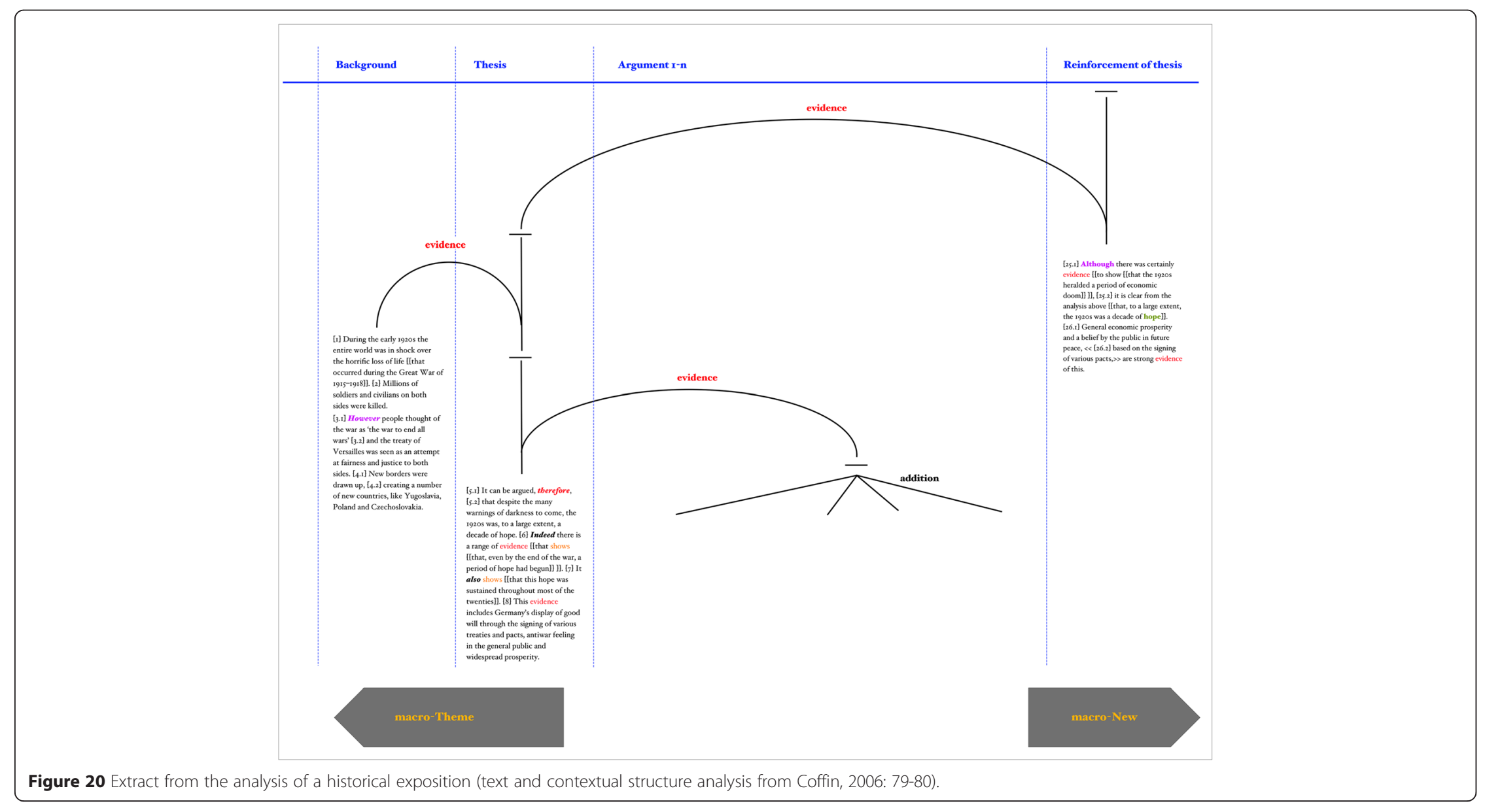


the same in argumentative expositions, as illustrated by the extract analysed in Figure 20; Coffin (2006: 79-80) presents the whole text with a contextual analysis of it as an exposition. The contextual element of "Reinforcement of the Thesis" is realized by the global nucleus of the text - the proposition or propositions where the central claim is made. This nucleus is presented as macro-New so that by the time readers have reached it they have processed the evidence for this claim (or if they skip to the end of the text - as one often does, they are presented with its punch line). The evidence is often organized as a nuclear segment providing a generalization about the evidence, and this segment is often within the macro-thematic zone of the text. In the case of the text analysed in Figure 20, this text segment realizes the "Thesis" element of the contextual structure.

There is a great deal more to be said about the mapping of the logical analysis of texts as rhetorical complexing to the textual mapping of texts as waves of information, and also about experiential and interpersonal considerations; but I hope that I have given a sense of the potential of registerial cartography based on both contextual and semantic analysis.

\section{Working with registerial maps}

The development of registerial cartography is still only in very early stages because there is a huge effort involved in developing the kinds of maps I have sketched above - even though I have focussed mostly on field of activity and logico-semantic relations. At the same time, I think we have actually reached a point in the development of register maps where we can work productively with them. In this final section, I will give two brief examples of how such maps can be deployed, one from educational linguistics and one from healthcare communication studies.

\section{Educational linguistics}

In the study of the role of language in education, registerial maps have been used to show the registerial composition of particular school subjects, to bring out learner paths through these subjects, to trace the development of student writing longitudinally, and to trace the selection of registers in sequences of text books. I will illustrate a couple of these uses.

School subjects range over different contexts; the contextual range differs from one subject to another, as does the corresponding registerial range. All subjects are likely to embody a considerable registerial range, but these registerial ranges will differ from one subject to another. For example, secondary school history, English and science have quite different registerial ranges: see Figure 21. This summary is based on the studies of the development of writing in these subjects - Christie and Derewianka (2008) and Christie (2012); both these recent books bring out the ontogenetic sequence of learning in the (Australian) primary and secondary school system, and for an earlier summary, see Unsworth, Len (2000); for history, see also Coffin (2006), and for science, see also Halliday \& Martin (1993), Unsworth (1995), Veel (1997), and the work on chemistry in text books by Pun (2011) that I will draw on here. Martin and Rose (2008) provide a summary of genres of writing used in various school subjects. Less work has been done on university disciplines, but see Parodi (2010) for genre profiles for four university disciplines - discussed in terms of the registerial cartography used here in Matthiessen (2009a, 2010). 


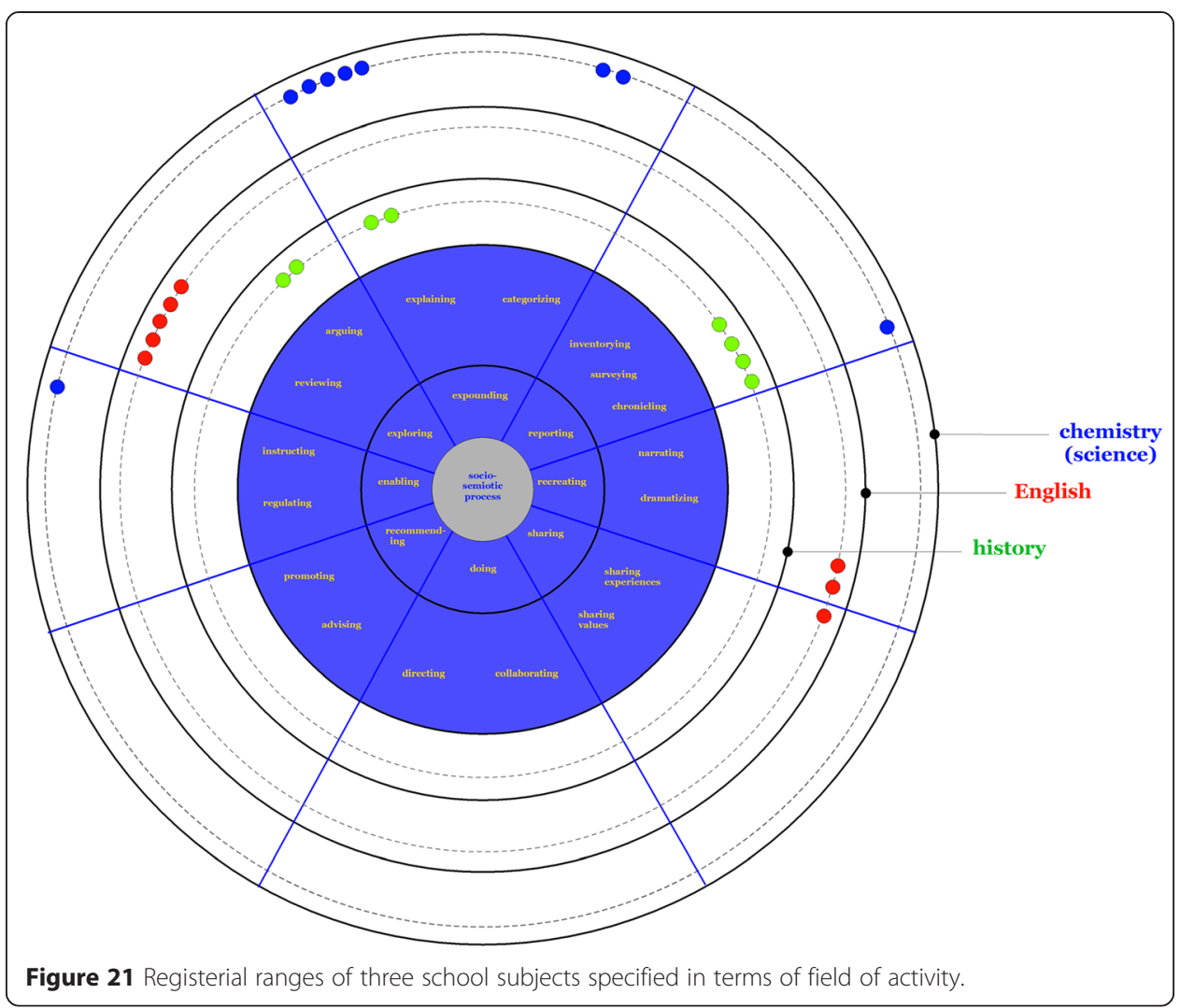

In history, the registerial range includes texts in 'reporting', 'expounding' and 'exploring' contexts; and these are sequenced in the primary and secondary school curricula: see Figure 22. In late primary school, the registerial range of history is first formed in the 'reporting' sector - not surprisingly, since this is the sector where flows of event are chronicled. Building on their experience with stories, students learn to produce recounts, managing successive settings in time, and then biographical recounts. In early secondary school, staying within the 'reporting' sector, they learn to add cause to time, and begin to write historical accounts. In mid secondary school, learners shift from time to cause - from chronicling events to explaining them: they move from the 'reporting' sector into the 'expounding' one, organizing the texts they write in terms of cause rather than time, in the form of historical explanations. Finally, in mid secondary school, they shift from external cause to internal cause; they move from the 'expounding' sector to the 'exploring' one, and learn to produce expositions and discussions such as the historical exposition analysed in Figure 20 above, which is organized globally in terms of the rhetorical relation of 'evidence' - internal cause. In late secondary school, they turn from history to "meta-history", i.e. historiography.

In subject English, students learn to write stories ("recounts" and "narratives") within the 'recreating' sector, both personal ones - thus sharing experience rather than recreating it, and imaginative ones - which are truly 'recreating' in nature; and they learn to write about stories and other texts within the 'exploring' sector - "to respond and to evaluate other texts", as Christie and Derewianka (2008: 58) put it. To begin with, they draw on their experience with sharing personal values in the 'sharing' sector ("personal response"), but then they move onto "reviews", "character analyses" and "thematic 


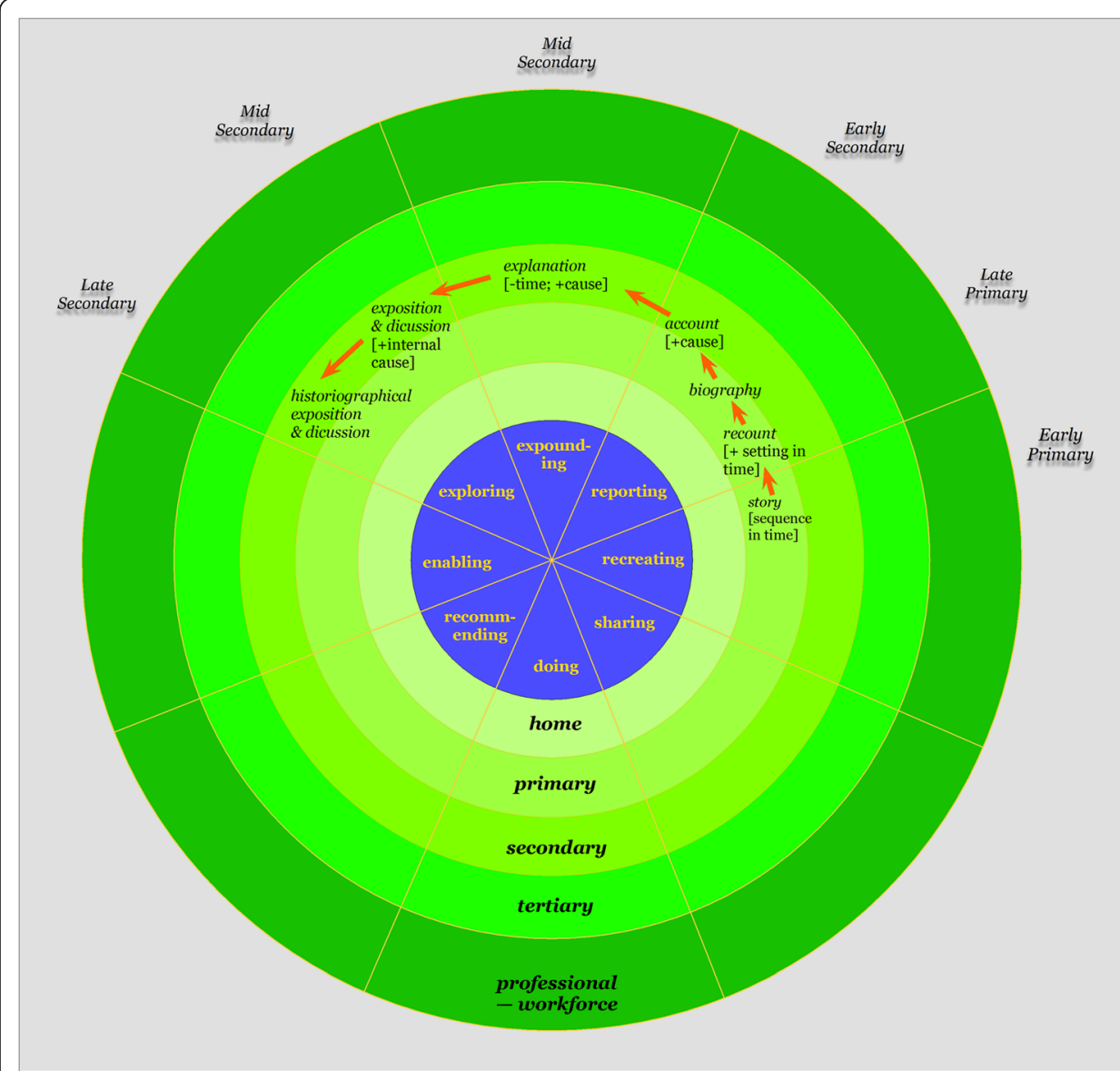

Figure $\mathbf{2 2}$ Learner path in history from primary through late secondary school (based on information in Coffin, 2006, and Christie and Derewianka 2008).

interpretations", all within the 'exploring' sector. In subject English, there is thus a sense in which students start with personal values and experiences in the 'sharing' sector, and then move in two directions - on the one hand, into the realm of the imaginary in the 'recreating' sector (although children will of course have had a great deal of experience with imaginative stories before school); and on the other hand, into the realm of the more objective and analytical mode of engagement with text in the 'exploring' sector.

In science, different fields of activity - 'enabling', 'doing' 'reporting' and 'expanding' complement one another as activities undertaken by apprentice scientists as they learn the scientific method linking data to theory: see Figure 23, which represents the situation in chemistry. The figure is based on Pun's (2011) study of secondary school chemistry text books used in Hong Kong, although the 'doing' field of activity is of course undertaken outside the text book in the laboratory ${ }^{\mathrm{m}}$; but the registerial range he identifies is very similar to what has been found in studies of science writing by learners in Australian schools by Halliday \& Martin (1993), Unsworth, (1995), Veel (1997), Christie and Derewianka $(2008)^{n}$. In chemistry, learners have to master the "scientific method" as it is manifested in text types operating in different contexts. In 'enabling' contexts, students of chemistry meet lab procedures, helping them learn how to set up and conduct an 


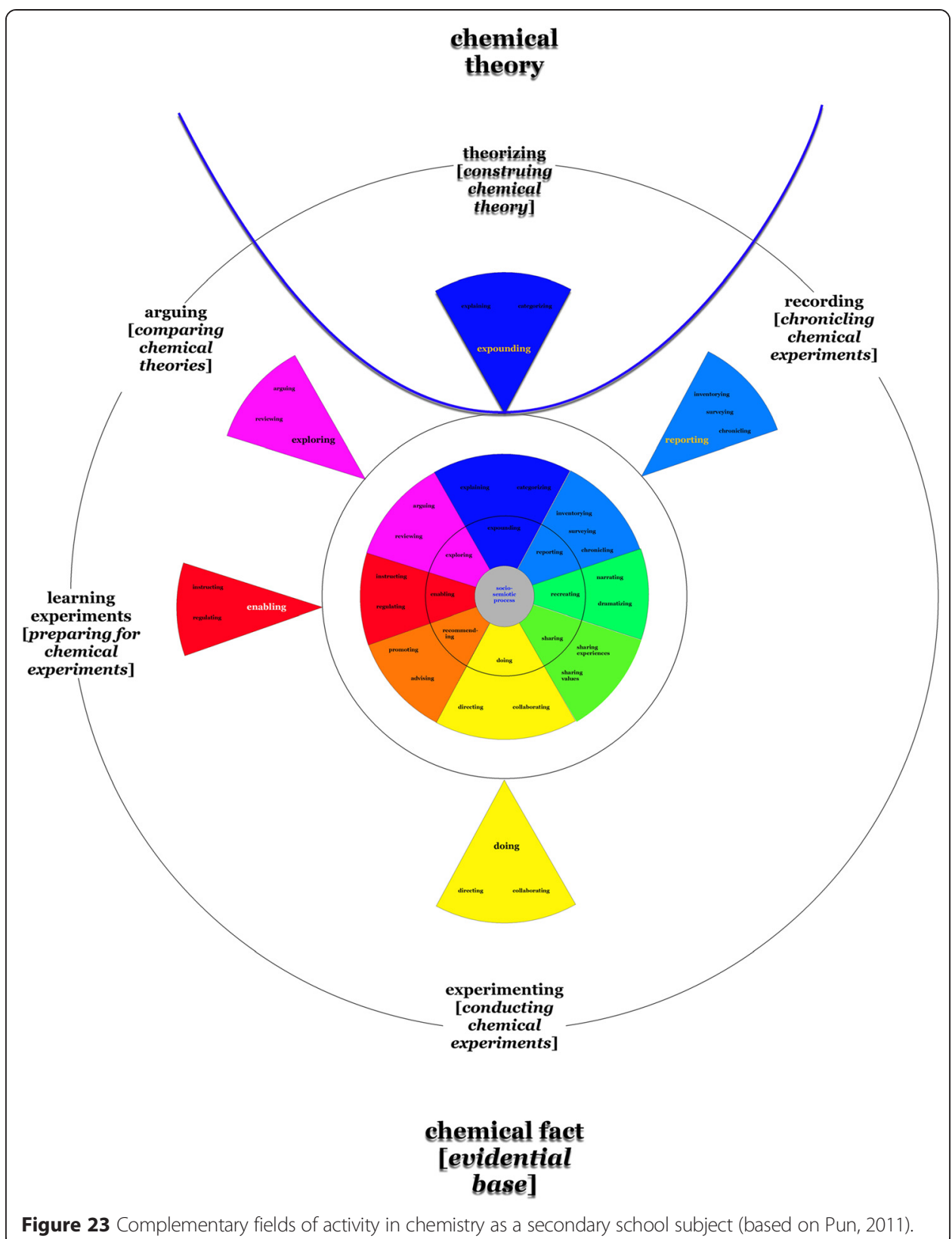

experiment; and this may be supplemented by demonstrations of experiments given by the teacher in class. In 'doing' contexts, students carry out experiments, under the guidance of their teacher; these experiments of course conducted in a lab, and the text is spoken - "language in action", serving to facilitate the social process of conducting a scientific experiment.

In 'reporting' contexts, students chronicle their experiment, recording the steps and producing a "procedural recount". In these fields of activity - 'enabling, 'doing' and 'reporting', students focus on chemical data; they engage with the evidential base upon which chemical theory is built. For example, they initiate, observe and record chemical reactions like different forms of oxidization. In contrast, in 'expounding' contexts, students learn chemical theory; they learn to generalize about chemical phenomena - to 
theorize them through categorization (e.g. the periodic table) and explanation (e.g. oxidization, or the process of refining, illustrated in Figure 16 above). Using the registerial map in Figure 23, we can begin to investigate how data and theory are presented to students of chemistry; and how they complement one another in the construction of chemistry as a subject - or (in universities) as a discipline.

In educational linguistics - broadly conceived as involving all aspects of language in education, it is thus possible to use the registerial map originally presented in Figures 4 and 5 to develop registerial profiles of different school subjects, to bring out registerial complementarities within a given subject, to identify learner paths involving the gradual development of registerial repertoires, and also to begin to give an account how a subject is constituted contextually and registerially. This last aspect can be thought of as interpreting a subject in institutional terms as an institutional domain learning.

\section{Healthcare communication and medical discourse studies}

As illustrated in the previous section, registerial maps can be used to profile and compare the registerial make-up of different school subjects; and in profiling a subject, we can begin to relate the profile to its institutional domain, as illustrated for chemistry in Figure 23.

In a similar way, we can use registerial maps to shed light on other institutional domains or even whole institutions - or, even more ambitiously, whole cultures. In current research, we are using registerial maps to investigate communication in

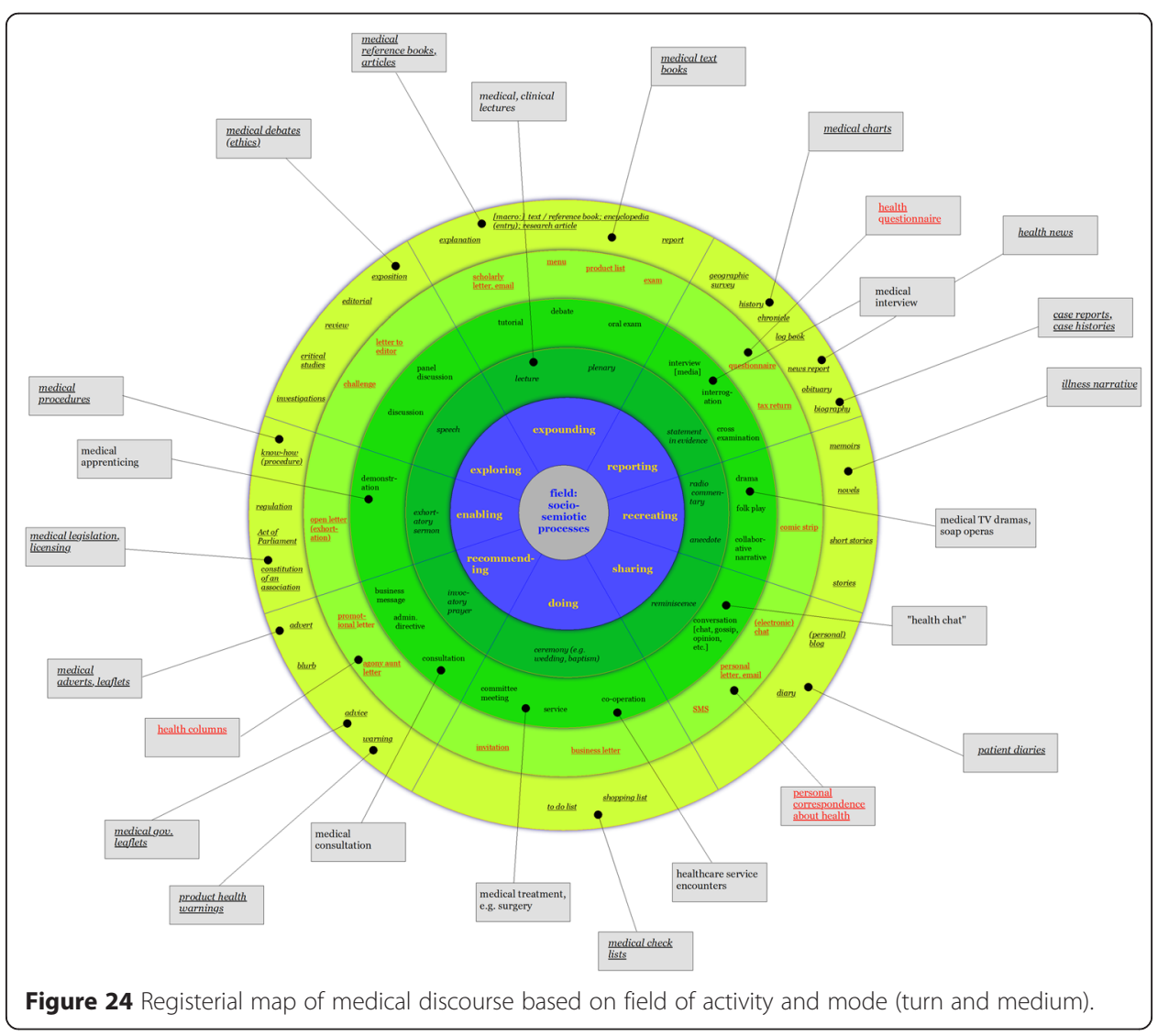


institutions of healthcare. Here it is helpful to begin very broadly by sketching the outlines of a registerial map of healthcare communication and medical discourse (cf. Matthiessen 2013): see Figure 24. In this map, I have only represented the primary distinction in delicacy among fields of activity; but I have added distinctions in mode to the map in the form of concentric circles surrounding "field: socio-semiotic processes": the first circle represents spoken monologic contexts, the second spoken dialogic ones, the third written dialogic ones, and the fourth written monologic ones.

What the registerial map in Figure 24 shows is how pervasive our concern with health, illness, disease, healthcare and medicine really is: these different aspects of life are processed in innumerable contexts - only some of which are sampled in the registerial map. Thus while the most obvious gateway for somebody suffering from a health problem may be a medical consultation - spoken and dialogic, within the 'recommending' sector, she or he is likely to engage with texts in other contexts. Before the consultation, this person is likely to have looked up reference material, in print or on the web, either general information about the human body ${ }^{\circ}$ ('expounding') or advice about how to deal with the health problem ('recommending', probably written monologic). After the consultations, he or she may go back to these sources, and is also likely to read texts in 'enabling' contexts such as the instructions that come with medication prescribed by a doctor. Throughout the whole process, he or she is also likely to have chatted about his or her problems with family and friends ('sharing') and perhaps followed medical news reports ('reporting'). Given the centrality to our lives of health and wellbeing, and ways of dealing with illness and disease, it surely not surprising that medical dramas of a variety of flavours (from soap opera to pretend documentary) have become so popular ('recreating').

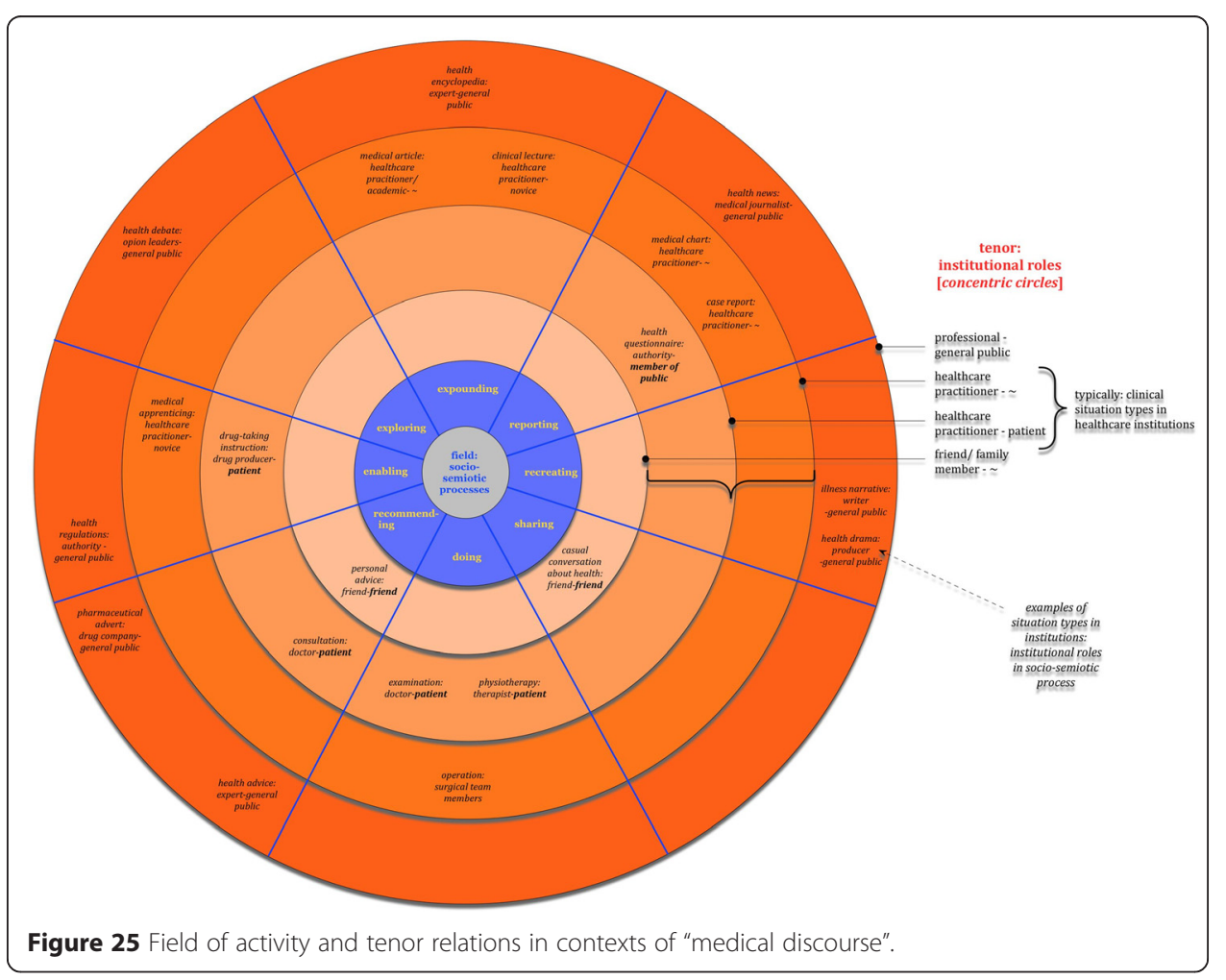


To complement the registerial map in Figure 24, I have intersected field of activity with tenor relations in Figure 25. This registerial map is thus based on field and tenor rather than on field and mode. Out of the various tenor relationships that we need to consider (e.g. institutional role, status role, sociometric role), I have concentrated on institutional role (also called agentive role) - the roles people play in a situation type by virtue of their contribution to the institution. By scanning it, we can get a sense of what role relationships a (potential) patient may enter into.

One focus in our own healthcare communication research, in both Australia and Hong Kong, has been on communication in emergency (or accident and emergency) departments in large hospitals (for the foundational EDCOM project, see Slade et al. 2008; Slade et al. 2011). From the point of view of the patient who enters an emergency department, the organizing principle of their visit will be their "journey" through the department, from triage to admission to a hospital ward or, hopefully, discharge. These patient journeys typically involve a bewildering sequence of encounters with different nurses and doctors, starting with triage. The complexity of the journey is in itself a challenge to patients. This complexity involves a move from one field of activity to another. During this journey, the situation type of medical consultation - 'recommending: advising' - is nuclear; but the patient is also very likely to experience supporting situation types, including medical history ('reporting'), examination ('doing') and treatment (again 'doing').

\section{Conclusion}

In this paper, I have been concerned with registerial cartography as an area of research, using "registerial cartography" to refer to the task of mapping a domain in terms of the registers that can be said to characterize it. I have located the domain to be mapped in registerial cartography in terms of the hierarchy of stratification and the cline of instantiation: see Figure 2 above. Register variation is semantic variation - that is, variation in the deployment of the meaning potential of a language; but it is variation that correlates with different settings of the contextual variables of field, tenor and mode, so when we map out the patterns of semantic variation, we do so in relation to context. Here I have focussed on field - in particular, on the field of activity within context, the socio-semiotic process those involved in the context are engaged in (e.g. Figure 5 above); but I have also illustrated briefly how the different fields of activity can be intersected with mode (Figure 24 above) and with tenor (Figure 25 above).

The project of registerial cartography is both large-scale and long-term. I have only been able to give illustrative analyses of texts operating in four out of the eight primary fields of activity set out in Figure 5. It would certainly be possible to add many more illustrations; but it is also necessary to push ahead and extend the coverage of the analysis very considerably so that we can develop descriptions of a far greater range of registers.

Having introduced and illustrated registerial maps, I gave some examples of how they can be deployed in two areas - educational linguistics and healthcare communication studies. With registerial maps, we can profile and compare different school subjects (and university disciplines, as shown by Parodi 2010); we can chart learner paths through the whole school system, from primary to secondary; we can identify the registers that a 
patient is likely to have to engage with both within and outside institutions of healthcare; and we can trace patient journeys through a hospital department. In addition to these two areas, there are several more where we have benefited from the use of registerial maps, including language description (cf. Teruya 2007), translation studies, second/foreign language learning studies (cf. Matthiessen 2009a) - under the general heading of educational linguistics, and multimodal studies (cf. Matthiessen 2009b).

\section{Endnotes}

${ }^{a}$ For an exploration of registerial cartography applied to various semiotic systems, see Matthiessen (2009b).

${ }^{\mathrm{b}}$ This distinction must be viewed in relation to an ordered typology of systems operating in different phenomenal realms (see e.g. Halliday and Matthiessen 2006; and, in relation to discourse analysis, Matthiessen, 2014): $4^{\text {th }}$-order systems: semiotic systems $-3^{\text {rd }}$-order systems: social systems $-2^{\text {nd }}$-order systems: biological systems $-1^{\text {st }}$-order systems: physical systems. Since the typology is an ordered one, each higher order system incorporates the properties of lower-order ones. Thus semiotic systems are also social systems, so "semiotic processes" are also social; but "social processes" are not semiotic - they are processes of behaviour, not processes of meaning.

"I use the term "contextual structure" simply to make it explicit that these structures belong to the stratum of context. More common terms in systemic functional linguistics include generic structure (as in Hasan 1978, 1984, generic structure potential) and schematic structure (as in Martin 1992a).

${ }^{\mathrm{d}}$ Here I just want to illustrate the point that when we extend the account in delicacy, there are different ways of grouping types of activity into systems. For an insightful, somewhat different, classification of explanation "genres in science", see Martin and Rose (2008: 167).

${ }^{\mathrm{e}}$ If they are not realized semantically in language, they may be realized through some other semiotic system; or they realization may bypass semiotic systems and be stated directed in terms of categories in social systems: see Matthiessen (2014).

${ }^{\mathrm{f}}$ My presentation here draws centrally on the work Bill Mann, Sandy Thompson and I started over 30 years ago on what came to be known as Rhetorical Structure Theory (RST; e.g. Mann, Matthiessen and Thompson 1992). Since this "classical" version of RST, there have been various further developments. In my own work, I have incorporated RST into systemic functional linguistics, one aspect of which has been to systemicize the rhetorical relations (cf. Matthiessen 2002). It is this version that I will present here. One source of inspiration was Halliday's (1981) question "how is a text like a clause?". I asked the supplementary question "how is a text like a clause complex?"; and it seemed to me that a rhetorical-relational analysis of a text based on RST brings out the answer: a text is a rhetorical complex.

${ }^{\mathrm{g}}$ When system networks are represented more formally, this recursive kind of system needs additional attention: see Matthiessen (1988) and Bateman (1989).

${ }^{\mathrm{h}}$ The contrast between proposition and proposal derives from Halliday's (1984) work on the interpersonal system of speech function: propositions involve the exchange of information - statements (giving information) and questions (demanding information) 
whereas proposals involve the exchange of goods-\&-services - offers (giving goods-

\&-services) and commands (demanding goods-\&-services).

${ }^{i}$ Source: http://www.hko.gov.hk/wservice/warning/smse.htm

'Source: The Sydney Morning Herald, October 1998. For the lexicogrammatical analysis of another news report of a maritime disaster, see Matthiessen (1995a).

${ }^{\mathrm{k}}$ Thus advertisements belong to the category of text identified by Martin (1992a,b) as macro-proposals.

ISource: http://store.apple.com/hk/reviews/TR792Z/A?fnode=MTY1NDA1MQ

${ }^{\mathrm{m}}$ There are a couple of minor motifs in the text books Pun (2011) examined: warnings in 'recommending' contexts (warnings about dangers in the lab) and expositions in 'exploring' contexts - arguing about ideas in chemistry.

${ }^{\mathrm{n}}$ These are concerned mainly with "written science"; for "spoken science", see Lemke (1990).

${ }^{\circ}$ For a very insightful and personal account, see Fleischman (2001).

Competing interests

The authors declare that they have no competing interests.

Received: 23 March 2015 Accepted: 15 April 2015

Published online: 03 November 2015

References

Bateman, John. 1989. Dynamic systemic-functional grammar: a new frontier. Word 40(1-2): 263-287.

Christie, Frances. 2012. Language education throughout the school years: a functional perspective. Oxford: Wiley-Blackwell.

Christie, Fran, and Beverley Derewianka. 2008. School discourse: learning to write across the years of schooling. London \& New York: Continuum.

Christie, Frances, and J.R. Martin (eds.). 1997. Genre and institutions: social processes in the workplace and school. London: Cassell.

Coffin, Caroline. 2006. Historical discourse. London \& New York: Continuum.

Eggins, Suzanne, and Diana Slade. 2005. Analysing casual conversation. London: Equinox.

Fleischman, Suzanne. 2001. Language and medicine. In The handbook of discourse analysis, ed. Tannen Deborah and Heidi E Hamilton, 470-502. Oxford: Blackwell.

Ghadessy, Mohsen (ed.). 1988. Registers of written English: situational factors and linguistic features. London: Pinter.

Ghadessy, Mohsen (ed.). 1993. Register analysis: theory and practice. London \& New York: Pinter.

Gu, Yueguo. 2002. Towards an understanding of workplace discourse - a pilot study for compiling a spoken Chinese corpus of situated discourse. In Theory and Practice of Professional Discourse, ed. Christopher Candlin, 137-185. Hong Kong: CUHK Press.

Halliday, M.A.K. 1970. "Functional diversity in language, as seen from a consideration of modality and mood in English." Foundations of Language 6: 322-361. Reprinted in Halliday, M.A.K. 2005. Studies in English Language. Volume 7 in the Collected Works of M.A.K. Halliday, edited by Jonathan J. Webster. London \& New York: Continuum. Chapter 5: 164-204

Halliday, MAK. 1973. Explorations in the Functions of Language. London: Edward Arnold.

Halliday, MAK. 1978. Language as social semiotic: the social interpretation of language and meaning. London: Edward Arnold.

Halliday, M.A.K. 1981. "Text semantics and clause grammar: some patterns of realization." Seventh LACUS Forum. Columbia: Hornbeam Press. 31-59. Reprinted as "Text semantics and clause grammar: how is a text like a clause?" in Halliday, M.A.K. 2002. On grammar. Volume 1 of Collected Works of M.A.K. Halliday. Edited by Jonathan Webster. London \& New York: Continuum. Chapter 9: 219-260.

Halliday, M.A.K. 1984. "Language as code and language as behaviour: a systemic-functional interpretation of the nature and ontogenesis of dialogue." In M.A.K. Halliday, Robin P. Fawcett, Sydney Lamb \& Adam Makkai (eds.), The semiotics of language and culture. London: Frances Pinter. Volume 1: 3-35. Reprinted in Halliday, M.A.K. 2003. On Language and Linguistics. Volume 3 of Collected Works of M.A.K. Halliday. Edited by Jonathan Webster. London \& New York: Continuum. Chapter 10: 226-250.

Halliday, MAK. 1985. Spoken and written language. Geelong, Vic.: Deakin University Press.

Halliday, MAK. 1987. Spoken and written modes of meaning. In Comprehending oral and written Language, ed. Horowitz Rosalind and S Jay Samuels, 55-82. New York: Academic Press.

Halliday, MAK. 1988. On the language of physical science. In Registers of Written English: situational factors and linguistic features, ed. Mohsen Ghadessy, 162-178. London \& New York: Pinter Publishers.

Halliday, M.A.K. 1991. "The notion of 'context' in language education." In Thao Le \& Mike McCausland (eds.), Interaction and development: proceedings of the international conference, Vietnam, 30 March - 1 April 1991. University of Tasmania: Language Education. 1-26. Reprinted in M.A.K. Halliday (2007), Language and education. Volume 9 in the Collected Works of M.A.K. Halliday, edited by Jonathan Webster. London \& New York: Continuum. 269-290.

Halliday, M.A.K. 1994. "Language and the theory of codes." In Alan Sadovnik (ed.), Knowledge and pedagogy: the sociology of Basil Bernstein. Norwood, N.J.: Ablex. 124-142. Reprinted in MA.K. Halliday (2007), Language and 
society. Volume 10 in the Collected Works of M.A.K. Halliday, edited by Jonathan J. Webster. London \& New York: Continuum. Chapter 8: 231-246

Halliday, M.A.K. 2001. "On the grammatical foundations of discourse." In Ren Shaozeng, William Guthrie \& I.W. Ronald Fong (eds.), Grammar and discourse: proceedings of the International Conference on Discourse Analysis, University of Macau (in conjunction with Tsinghua University, China), 16-18 October 1997. Macau: University of Macau Publication Centre. 47-58. Reprinted in M.A.K. Halliday, 2006. Studies in Chinese Language. Edited by Jonathan J. Webster. London \& New York: Continuum. 346-367

Halliday, M.A.K. 2002. "Computing meanings: some reflections on past experience and present prospects." In Guowen Huang \& Zongyan Wang (eds.) Discourse and Language Functions. Shanghai: Foreign Language Teaching and Research Press. 3-25. Reprinted in M.A.K. Halliday (2005), Computational and quantitative studies. Volume 6 in the Collected Works of M.A.K. Halliday, edited by Jonathan Webster. London \& New York: Continuum. 239-267.

Halliday, MAK, and Ruqaiya Hasan. 1976. Cohesion in English. London: Longman.

Halliday, MAK, Angus Mclntosh, and Peter Strevens. 1964. The linguistic sciences and language teaching. London: Longman. Halliday, MAK, and Christian MIM Matthiessen. 2004. An introduction to functional grammar. 3rd Edition. London: Arnold. Halliday, MAK, and Christian MIM Matthiessen. 2006. Construing experience through meaning: a language-based approach to cognition, Studyth ed. London \& New York: Continuum.

Halliday, MAK and JR Martin. 1993. Writing science: literacy and discursive power. London: Falmer.

Hasan, Ruqaiya. 1973. Code, register and social dialect. In Class, Codes and Control: applied studies towards a sociology of language, vol. 2, ed. Basil Bernstein, 253-292. London: Routledge \& Kegan Paul.

Hasan, Ruqaiya. 1978. Text in the systemic-functional model. In Current Trends in Text Linguistics, ed. Wolfgang Dressler, 228-246. Berlin: de Gruyter.

Hasan, Ruqaiya. 1984. "The nursery tale as a genre." Nottingham Linguistic Circular 13. Reprinted in Ruqaiya Hasan (1996), Ways of saying: ways of meaning: selected papers of Ruqaiya Hasan. Edited by Cloran, Carmel, David Butt \& Geoffrey Williams. London: Cassell. 51-72

Hasan, Ruqaiya. 1994. Situation and the definition of genre". In What's going on here: complementary studies of professional talk, ed. Allen D Grimshaw, 127-172. Norwood, N.J.: Ablex.

Hasan, Ruqaiya. 1999. Speaking with reference to context. In Text and Context in Functional Linguistics: Systemic Perspectives, ed. Mohsen Ghadessy, 219-328. John Benjamins: Amsterdam \& Philadelphia.

ledema, Rick, Susan Feez \& Peter White. 1994. Media literacy. (Write it right industry research report no. 2). Sydney: NSW, Department of Education, Disadvantaged Schools Program Metropolitan East.

Lam, Marvin, and Jonathan Webster. 2009. The lexicogrammatical reflection of interpersonal relationship in conversation. Discourse Studies 11(1): 37-57.

Lemke, Jay L. 1990. Talking science: language, learning and values. Norwood, N.J.: Ablex.

Longacre, Robert E. 1974. Narrative vs other discourse genres. In Advances in Tagmemics, ed. Ruth Brend, 357-376. Amsterdam: North-Holland.

Longacre, Robert E. 1996. The grammar of discourse, 2nd ed. New York: Plenum.

Lukin, Annabelle, Alison Moore, Maria Herke, Rebekah Wegener, and Wu Canzhong. 2008. Halliday's model of register revisited and explored. Linguistics and Human Sciences 4(2): 187-243.

Macnamara, Jim. 2010. The $21^{\text {st }}$ century media: (r)evolution — emergent communication practices. New York: Peter Lang.

Mann, William C, and Christian Matthiessen. 1991. Functions of language in two frameworks. Word 42(3): $231-249$.

Mann William, C, Christian M.I.M. Matthiessen, Sandra A Thompson, William C Mann, and Sandra A Thompson. 1992. Rhetorical Structure Theory and Text Analysis. USC/ISI Report. In Discourse Description: Diverse Linguistic Analyses of a Fund Raising Text, 39-78. Amsterdam: Benjamins.

Martin, JR. 1992a. English text: system and structure. Amsterdam: Benjamins.

Martin, JR. 1992b. Macro-proposals: meaning by degree. In Text description: diverse analyses of a fund raising text, ed. William C Mann and Sandra A Thompson, 359-395. Amsterdam: Benjamins.

Martin, J.R. 1993. Life as a noun. In Writing science: literacy and discursive power, ed. M.A.K. Halliday and JR Martin, 221-267. London: Falmer.

Martin, J.R. \& Christian M.I.M. Matthiessen. 1991. "Systemic typology and topology." In Frances Christie (ed.), Literacy in social processes: papers from the Inaugural Australian Systemic Functional Linguistics Conference, Deakin University, January 1990. Darwin: Centre for Studies of Language in Education, Northern Territory University. 345-383. Reprinted in J.R. Martin (2010), SFL theory, Volume 1 in the collected works of J.R. Martin, edited by Wang Zhenhua. Shanghai: Shanghai Jiao Tong University Press. 167-215.

Martin, J.R. and David Rose. 2008. Genre relations: mapping culture. London \& Oakville: Equinox.

Martin, J.R. and Peter R.R. White. 2005. The language of evaluation: appraisal in English. London \& New York: Palgrave Macmillan.

Matthiessen Christian M.I.M. 1988. Representational issues in systemic functional grammar. In Systemic functional perspectives on discourse, ed. James D Benson and William S Greaves, 136-175. Norwood, NJ: Ablex.

Matthiessen, Christian M.I.M. 1993. "Register in the round: diversity in a unified theory of register analysis." Mohsen Ghadessy (ed.), Register analysis: theory and practice. London: Pinter. 221-292.

Matthiessen, Christian M.I.M. 1995a. Lexicogrammatical cartography: English systems. Tokyo: International Language Sciences Publishers.

Matthiessen, Christian MIM. 1995b. THEME as an enabling resource in ideational "knowledge" construction. In Thematic developments in English texts, ed. Mohsen Ghadessy, 20-55. London \& New York: Pinter.

Matthiessen Christian, MIM. 2002. Combining clauses into clause complexes: a multi-faceted view. In Complex sentences in grammar and discourse: essays in honor of Sandra A. Thompson, ed. Bybee Joan and Noonan Michael, 237-322. Amsterdam: Benjamins.

Matthiessen, Christian MIM. 2006. Educating for advanced foreign language capacities: Exploring the meaning-making resources of languages systemic-functionally. In Advanced instructed language learning: The complementary contribution of Halliday and Vygotsky, ed. Heidi Byrnes, 31-57. Continuum: London \& New York. 
Matthiessen, Christian M.I.M. 2009a. "Meaning in the making: meaning potential emerging from acts of meaning." In Anniversary Issue of Language Learning 59 (Suppl 1): 211-235.

Matthiessen, Christian M.I.M. 2009b. "Multisemiotic and context-based register typology: registerial variation in the complementarity of semiotic systems." Ventola, Eija \& Arsenio Jesús Moya Guijarro (eds.). in 2009. The world shown and the world told. Basingstoke: Palgrave Macmillan. 11-38.

Matthiessen, Christian M.I.M. 2014. "Appliable discourse analysis." Fang Yan \& Jonathan J. Webster (eds.), Developing Systemic Functional Linguistics: theory and application. London: Equinox. 135-205.

Matthiessen, Christian M.I.M. 2013. "Applying Systemic Functional Linguistics in healthcare contexts." Text and Talk 33(4-5): 437-466.

Matthiessen, Christian MIM 1992. Interpreting the textual metafunction. Martin Davie \& Louise Ravelli (eds.) Advances in sytematic linguitics: recent theory and pratice. London: Pinter. 37-82

Matthiessen, Christian MIM, Diana Slade, and Mary Macken. 1992. Language in context: a new model for evaluating student writing. Linguistics Educ 4(2): 173-195.

Matthiessen, Christian M.I.M. \& Jack Pun. forthcoming "Expounding knowledge through explanations: generic types and rhetorical-relational patterns."

Matthiessen, Christian \& Kazuhiro Teruya. 2015. "Registerial hybridity: indeterminacy among fields of activity." In Donna Miller \& Paul Bayley (eds.), Permeable contexts and hybrid discourses. London: Equinox.

Matthiessen, Christian M.I.M., Kazuhiro Teruya, and Marvin Lam. 2010. Key terms in systemic functional linguistics. London \& New York: Continuum.

Nanri, Keizo. 1993. An attempt to synthesize two systemic contextual theories through the investigation of the process of the evolution of the discourse semantic structure of the newspaper reporting article. University of Sydney: Ph.D. thesis.

Parodi, Giovanni (ed.). 2010. Discourse genres in Spanish: academic and professional connections. Amsterdam: Benjamins.

Pun, Kwok Hung Jack. 2011. Analysis of Hong Kong science textbooks using systemic functional linguistics. MA thesis: The Hong Kong Polytechnic University, Department of English.

Shirky, Clay. 2010. The cognitive surplus: creativity and generosity in a connected age. New York: The Penguin Press.

Slade, Diana, Marie Manidis, Jeannette McGregor, Hermine Scheeres, Jane Stein-Parbury, Roger Dunston, Nicole Stanton, Eloise Chandler, Christian Matthiessen, and Maria Herke. 2011. Communicating in hospital emergency departments: final report. Sydney: University of Technology.

Slade, Diana, Hermine Scheeres, Marie Manidis, Christian MIM Matthiessen, Rick ledema, Maria Herke, Jeannette McGregor, Roger Dunston, and Jane Stein-Parbury. 2008. Emergency Communication: The discursive challenges facing emergency clinicians and patients in hospital emergency departments. Discourse Commun 2(3): 289-316.

Steele, Julie, and Noah Iliinsky (eds.). 2010. Beautiful visualization: looking at data through the eyes of experts. Inc: O'Reilly Media.

Teruya, Kazuhiro. 2007. A systemic functional grammar of Japanese. 2 volumes. London \& New York: Continuum.

Thrower, Norman JW. 2008. Maps and civilization: cartography in culture and society, 3rd ed. Chicago \& London: The University of Chicago Press.

Unsworth, Len. 1995. How and Why: recontextualizing science explanations in school science books. Sydney University: Ph.D. thesis.

Unsworth, Len. (ed.). 2000. Researching language in schools and communities: functional linguistic perspectives. (Re-issued 2005.) London: Cassell.

Veel, Robert. 1997. Learning how to mean — scientifically speaking: apprenticeship into scientific discourse in the secondary school. In Genre and institutions: social processes in the workplace and school, ed. Frances Christie and J.R. Martin, 161-195. London: Cassell.

\section{Submit your manuscript to a SpringerOpen ${ }^{\circ}$ journal and benefit from:}

- Convenient online submission

- Rigorous peer review

- Immediate publication on acceptance

- Open access: articles freely available online

- High visibility within the field

- Retaining the copyright to your article

Submit your next manuscript at $>$ springeropen.com 